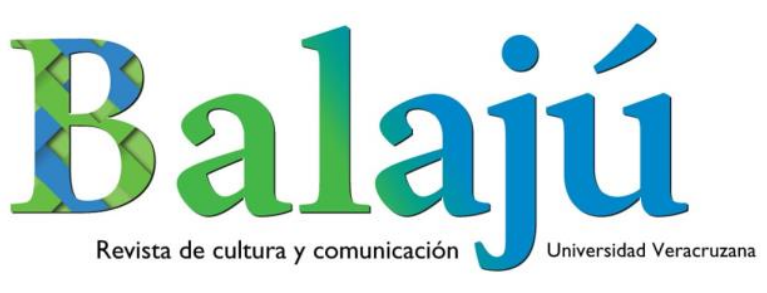

\author{
ISSN2448-4954 \\ No. 9, Año 5 \\ Agosto-Diciembre 2018
}

https://doi.org/10.25009/blj.voig.2560

\title{
La protesta estudiantil Argentina a un siglo del "Grito de Córdoba": una aproximación a su fenomenología
}

\section{The student protest in Argentina a century from the "Grito de Córdoba": an approach to its} phenomenology

\author{
Luis Carlos Castro Riaño1 \\ https://orcid.org/0000-0002-4033-5089
}

RESUMEN: En la Argentina la reforma universitaria de 1918 representa el momento a partir del cual el estudiantado se configura como sujeto político; desde entonces el accionar de este sector ha sido continuo, salvo algunos lapsos, y hoy por hoy hace parte del acervo cultural de la vida universitaria nacional. En este artículo indago en los hechos en los que se ha materializado, reviso su devenir y analizo las tramas que lo insuflan. Para ello realizo un recorrido que avanza desde sus primeros atisbos hasta nuestros días, observando su cómo y su por qué, mediante el uso de categorías que aluden a la estructura, a la identidad y, en particular, al componente cultural de la cuestión en tanto fenómeno social. El objetivo, a propósito de la conmemoración de aquel hito, es elaborar un mapa de la trayectoria de la protesta estudiantil en el país austral, y de las dinámicas que intervienen en su constitución, implementando enclaves analíticos poco usuales en la literatura local que la aborda.

PALABRAS CLAVE: Estudiantes, organización, agrupaciones, recursos, demandas

ABSTRACT: In Argentina, the university reform of 1918 represents the moment from which the student body is configured as a political subject; since then, the activity of this sector has been continuous, except for a few lapses, and forms part of the cultural heritage of national university life to this day. In this article, I investigate how this student activism has materialized, as well as its evolution and the narratives that drive it. To do so, I journey from its earliest moments to the present, observing its how and why, by means of categories that refer to structure, identity, and especially, the cultural component of the social phenomenon in question. The objective, framed by the centennial commemoration of the 1918 milestone, is to map the trajectory of student protest in the country and the dynamics involved in its constitution, implementing analytical strategies seldom seen in the local literature on the subject.

KEYWORDS: Students, organization, groups, resources, demands.

\footnotetext{
${ }^{1}$ Doctorando y magíster en Ciencias Sociales, Universidad Nacional de la Plata (UNLP). Licenciado en Educación, Unipanamericana. Correo electrónico: lucacas2010@hotmail.com

Fecha de recepción: 24/09/2018. Aceptado: 30/01/2019
} 


\title{
La protesta estudiantil Argentina a un siglo del "Grito de Córdoba": una aproximación a su fenomenología
}

\begin{abstract}
Hombres de una República libre, acabamos de romper la última cadena que, en pleno siglo $X X$, nos ataba a la antigua dominación monárquica y monástica. Hemos resuelto llamar a todas las cosas por el nombre que tienen, Córdoba se redime. Desde hoy contamos para el país con una vergüenza menos y una libertad más. Los dolores que quedan son las libertades que faltan. Creemos no equivocarnos, las resonancias del corazón nos lo advierten: estamos pisando sobre una revolución, estamos viviendo una
\end{abstract} hora americana...2

(ROCA 1918)

\section{Introducción}

La Reforma Universitaria Argentina de 1918 o el también llamado «Grito de Córdoba», fue un evento que pasó a la historia, entre otras cosas, porque ambientó la emergencia del estudiantado como sujeto político y estableció los principios generales de la lucha de este sector a nivel latinoamericano. El hecho motivó la conjugación de múltiples procesos orientados a la subversión del orden social y fue el producto de acciones organizadas que, en efecto, transformaron la lógica de funcionamiento de una institución con incidencia directa en el conjunto de la sociedad. Los universitarios se masificaron, a nivel nacional, gracias al accionar mancomunado de varias agrupaciones estudiantiles que lograron el apoyo de las organizaciones obreras de la época. Su objetivo se transformó, de forma extraordinaria, desplazándose del reclamo de asuntos académicos a la demanda por participación política en el gobierno universitario, acusado de confesional y anacrónico por desarrollarse en un ambiente burocrático católico que además databa del siglo XVII.

La radicalización de las demandas maduró en el primer Congreso Nacional de Estudiantes realizado entre el 20 y 30 de julio de ese año. La autonomía universitaria; el cogobierno con representación estudiantil; la gratuidad y libre asistencia a clase; la libertad de cátedra, su periodicidad; el régimen de concursos; la docencia libre; la investigación; y la extensión universitaria (Portantiero 1978), fueron demandas muy bien recibidas por los educandos universitarios de la región -algunas también lo serían para los estudiantes europeos cincuenta años más tarde, en el mayo francés del 68-. El movimiento reformista pronto recorrió otros Estados latinoamericanos. En la década del 1920 hizo presencia en Chile, Perú, Cuba y Colombia. En la del treinta el turno fue para México, Paraguay y Brasil; en algunos países dio pie a la fundación de partidos políticos (Portantiero 1978; Mariátegui 2012).

La movilización que subyace a este fenómeno alberga toda una trama social que se desarrolló en dos etapas. La primera tiene su inicio en diciembre de 1917 con la denuncia de los estudiantes de Medicina de la Universidad Nacional de Córdoba (UNC), respecto al cese de los internados en el Hospital y a los procedimientos del cuerpo docente, pero oficialmente comienza el siguiente año lectivo, 10 de marzo de 1918, con varias manifestaciones callejeras, y la conformación del Comité Pro Reforma. Termina el 7 de mayo en medio de la intervención estatal a la universidad

2 Fragmento del Manifiesto Liminar, proclama del movimiento de la Reforma Universitaria, redactado por Deodoro Roca y difundido el 21 de junio de 1918 en Córdoba, Argentina. 
y el anuncio de un proyecto de reformas al estatuto de las universidades existentes3, que abría la participación del claustro docente en sus jefaturas. Durante este corto periodo, el 11 de abril, fue creada la Federación Universitaria Argentina (FUA), organismo que en la actualidad representa aproximadamente a millón y medio de estudiantes de todo el país.

El programa, autorizado por el propio presidente de la república4, establecía el mecanismo y plazos para la elección de consejos directivos, decanos y rector. El 15 de junio fue la fecha elegida para realizar el certamen electoral en la casa de estudios cordobesa. La segunda etapa comenzó ese día con la derrota del candidato de los estudiantes, el rechazo al proceso de elección, la insurrección violenta del estudiantado y la declaración de una huelga general a la que rápidamente se sumaron los educandos de las demás universidades nacionales; finalizó el 12 se septiembre de ese año, luego de varias asonadas estudiantiles, con una nueva intervención estatal que dio vía libre a la reforma, ahora radicalizada, avalando un hecho que marcó el antes y el después de la protesta de este sector en el país austral.

Desde entonces la movilización de este sector social ha sido continúa, pese a que no se constate una manifestación empírica que adquiera semejante envergadura, y a que la organización del gremio ha sido regulada e incluso cercenada -de manera brutal- en varias oportunidades. ¿Cuál ha sido el devenir de esta expresión en cien años de trayectoria?, ¿̇qué factores incentivan su persistencia?, ¿cómo conserva su continuidad en el tiempo ante el inevitable cambio generacional de sus protagonistas?, ¿sigue algún patrón en tanto activismo político?, ¿cuáles son los horizontes ideológicos que la delinean?, ¿̇cómo adquieren vida las problemáticas que denuncia?, ¿cómo se desarrollan sus sinergias?

En adelante sugiero las respuestas a estos interrogantes recuperando una tesis inédita 5 en la que preguntaba por la producción del sentido de la protesta estudiantil en este país. La investigación se concentra en dos casas de estudio: la Universidad de Buenos Aires (UBA) por ser considerada desde hace años como una «megauniversidad» (Delich 1986); y en la Universidad Nacional de la Plata (UNLP) por ser la institución que le sucede, en la capital de la provincia de Buenos Aires. Ambas representan centros educativos de larga trayectoria en los cuales el activismo político es intenso, y en donde operan organizaciones estudiantiles que hacen presencia en las demás universidades nacionales. El trabajo de campo, en particular el de observación, se desarrolló entre 2011 y 2017, en la Facultad de Ciencias Sociales y en la Facultad de Filosofía y Letras (FFyL) de la UBA, y en la Facultad de Humanidades y Ciencias de la Educación de la UNLP, claustros cuya incidencia electoral es bastante notoria en la dinámica de la política nacional, a diferencia de los demás.

Las unidades de análisis están representadas por nueve agrupaciones integrantes de los tres frentes que obtuvieron $67,43 \%$ de las elecciones del Centro de Estudiantes

\footnotetext{
3 Por aquellos días existía la Universidad de Buenos Aires, de la Plata, de Santa Fe, de Tucumán y de Córdoba.

4 Hipólito Irigoyen, figura relevante de la Unión Cívica Radical, dos veces elegido presidente de la República Argentina, una depuesto por golpe militar (1916-1922 y 1928-1930). Fue el primero en llegar al cargo por vía democrática; el tercero de origen popular.

5 Tesis de posgrado presentada para optar al grado de Magíster en Ciencias Sociales en la Facultad de Humanidades y Ciencias de la Educación de la Universidad Nacional de La Plata.
} 
de la FFyL, llevadas a cabo entre el 2 y el 6 de septiembre de 20136: Un Solo Grito (USG), Corriente Antiburocrática Universitaria Contra la Explotación (CAUCE), Sur Movimiento Universitario, Izquierda Socialista, Prisma, Movimiento Universitario Evita (MUE), Partido Socialista de los Trabajadores Unificado, Partido Obrero y Partido de los Trabajadores Socialistas (PTS). Esto porque el resultado obtenido allí, al igual que en años anteriores, marcó la tendencia electoral y se reflejó en las votaciones legislativas realizadas el mes siguiente. Sin embargo, el análisis incluye el examen de las estructuras y las prácticas de organizaciones como el Frente Estudiantil Revolucionario de Argentina (FER), la agrupación Franja Morada (FM), La Mella o la Mariátegui, entre otras7.

La construcción de datos correspondiente estuvo guiada por dos métodos, uno empírico y uno analítico. En cuanto al primero, buscando el favor de la producción del discurso conversacional que se puede hallar en un entrevistado, se realizaron un total de 18 «entrevistas en profundidad» a los integrantes de las agrupaciones mencionadas, siguiendo el tipo de «muestreo oportunista» para seleccionar a quienes eran más proclives a colaborar con la investigación (Cicourel 1982). El número de entrevistados fue adecuado para realizar un balance general de su práctica en tanto sus respuestas fueron notoriamente similares pese a que pertenecían a diferentes organizaciones. Con relación al segundo método, se examinó una cantidad considerable de material bibliográfico sobre el movimiento estudiantil a nivel nacional (libros, artículos, publicaciones en sitios web, etc.) y de documentos escritos por los propios integrantes de las agrupaciones. Este procedimiento permitió, entre otras cosas, el abordaje profundo de los fundamentos de cada agrupación, recuperar lo poco que se ha documentado sobre ellas y comprender la razón de las actividades que realizan continuamente. Durante todo el desarrollo de la investigación la búsqueda de información fue permanente, se incorporaron normas de transcripción al igual que pautas de análisis cualitativo y, finalmente, se triangularon los datos obtenidos contrastándolos para obtener una imagen más acabada del fenómeno estudiado.

El cuerpo del escrito está organizado en cuatro apartados: en el primero rastreo la trayectoria de la movilización estudiantil, desde principios del siglo XX hasta nuestros días, deteniéndome en los hechos más relevantes e identificando los sucesos que han posibilitado e impedido su unidad; en el segundo me concentro en las organizaciones estudiantiles, en sus protagonistas, es decir en los estudiantes, y en la estructura de sus organizaciones, elementos que asumo como recursos; en el tercero explico los fundamentos fenomenológicos intrínsecos a la consecución de sus objetivos; y en el último apartado expongo algunas conclusiones respecto a la lógica local de este hecho social en el país de estudio.

El objetivo general, a propósito del centenario de la reforma universitaria, es presentar un mapa de la cuestión que dé cuenta de la fenomenología de la protesta del estudiantado argentino -entendida ésta como el conjunto de prácticas que la caracterizan-, incorporando algunos presupuestos de la epistemología de los

\footnotetext{
${ }^{6}$ El resultado de dichas elecciones fue noticia en diarios como el Clarín (8 de septiembre), La Nación (8 de septiembre) y Página 12 (9 de septiembre). También fueron publicados en los siguientes sitios web: http://www.juventudinformada.com.ar/2013/o9/o8/en-vivo-resultados-de-las-elecciones-dela-uba / http://www.pagina12.com.ar/diario/universidad/10-227868-2013-08-30.html

7 Ver cuadros 1 y 2 en Anexo.
} 
movimientos sociales, puntualmente de la Teoría de la Movilización de Recursos, del enfoque de la identidad y de la perspectiva de la cultura; herramientas de análisis poco implementadas en la producción académica local especializada en este tema ${ }^{8}$. $\mathrm{Al}$ respecto considero prudente señalar, por supuesto no con el interés de demeritar a sus autores, que dicha producción académica, en general, además de loar el accionar de los universitarios, se basa en categorías marxistas, las cuales explican el fenómeno como producto de la lucha entre sectores sociales - «clases»-que pugnan por controlar su historicidad, pero dicen muy poco acerca de cómo aquéllas toman conciencia de ello y por lo tanto entran en disputa. Así, los trabajos que la componen, al presentar el antagonismo de la estructura social como única causa de la movilización estudiantil transforman uno de sus elementos en un factor excluyente. En otras palabras, suponen que las contradicciones socioeconómicas son el motor de la lucha del estudiantado, soslayando los procesos que intervienen en su conformación precisamente como actor social, y los que involucran la configuración de la conciencia colectiva manifiesta en los momentos visibles de la cuestión. El artículo presentado, por el contrario, pretende explicar el por qué, pero también el cómo, de las expresiones y sentidos que configuran esta forma de intervención social, observando las acciones fácticas de sus protagonistas y haciendo uso de enfoques que se aproximan a otras dimensiones sociales igualmente relevantes para su configuración y, desde luego, para su comprensión.

\section{Devenir histórico}

La protesta estudiantil en Argentina, abordada aquí en términos de «acción colectiva», esto es, como una serie de prácticas que subyacen a todo movimiento social (Tarrow 2004) las cuales conllevan múltiples procesos superpuestos, que por lo general ocurren de modo simultáneo (Melucci 1999), ha sido continua desde su inicio, hace un poco más de cien años, pese a las rupturas constitucionales que ha vivido la nación, pues sus actores, allende a las adversidades, se las han arreglado para manifestar su pensar aún en tiempos de barbarie Estatal (Califa 2007). Su trayectoria histórica se puede sintetizar en tres momentos claves para comprender su lógica y su persistencia, e ilustrar su configuración actual: el primero explica sus orígenes, al igual que su eclosión, y va de la última década del siglo XIX hasta la primera mitad del siglo XX; el segundo avanza de la década del cincuenta a la del ochenta y explica la politización y desmantelamiento; el tercero inicia con la transición a la democracia, y dilucida el resurgimiento y la formación actual.

\footnotetext{
${ }^{8}$ En realidad existe sólo una excepción en la producción académica Argentina y pertenece a Natalia Vega (2010). La autora analizó los repertorios discursivos y el modo en el que se construyeron las «identidades» en el movimiento estudiantil santafesino en el 66 durante la «Revolución Argentina». Destaco tres aportes pertinentes: 1) la importancia de atender tanto las voces de los actores como sus acciones en cuanto a la comprensión del fenómeno; 2) El reconocimiento de que la existencia de fracciones estudiantiles simpatizantes con el gobierno señalado y la agencia combativa, entre las agrupaciones nacionalistas/católicas y reformistas, es el producto de la construcción de identidades; y 3) la recuperación de acuerdos mínimos de diferentes paradigmas teóricos para «considerar a los movimientos sociales como formas de acción colectiva [...] que implican una actuación concertada con cierto grado de permanencia» (132).
} 


\subsection{Orígenes}

Las manifestaciones organizadas de la movilización de los estudiantes en el país austral se vienen registrando desde las vísperas del siglo XX. Varias de sus estructuras, al igual que sus sinergias y vías de expresión, continúan vigentes allende los cambios socioculturales propios de la época. Los centros de estudiantes organizaciones democráticas que atienden sus asuntos- se constituyeron iniciando la centuria; con las huelgas iniciales se cosechó la personería jurídica que permitía su funcionamiento al interior de las facultades. Los primeros líderes estudiantiles fundaron dos entes federativos que operan en la actualidad y han sido fundamentales para cohesionar y movilizar al estudiantado en diferentes oportunidades, tanto a nivel provincial como nacional: la Federación Universitaria de Buenos Aires (FUBA) en 1908 y la FUA en 1918 (Portantiero 1978).

De acuerdo con los especialistas en el tema, en un comienzo los intereses de su organización eran "auténticamente gremiales» (Buchbinder 2005), y el consenso colectivo expresaba la disidencia ante la elección de algunos profesores suplentes, frente a los planes de estudio, y a los plazos para la entrega de trabajos o exámenes. A diferencia de lo que ocurre hoy día, los principios ideológicos que atizaban su actuar contenían un carácter puramente universitario, aunque no por ello menos significativo para su formación intelectual y para el desarrollo de sus habilidades políticas (Buchbinder 1997).

El evento que denota la eclosión del estudiantado argentino en la escena política nacional fue la reforma universitaria de 1918. En ese momento se puede decir que inicia su acción colectiva contenciosa (Tarrow 2004). La querella que acarreó se nutrió de un contexto social efervescente a nivel global y local (la República Argentina se democratizaba con el Yrigoyenismo a flor de piel; México estaba consumando su revolución; recién había finalizado la Primera Guerra Mundial; en Rusia se materializaba la Revolución Bolchevique, etc.). A lo largo de los seis meses que duró es evidenciable un enfrentamiento que bien se puede entender en términos de «antagonismo», dado que agrupó a sus actores en una relación agonística «amigo/enemigo» (Schmitt 1998). La lógica de las coaliciones que generó este hecho también persiste en nuestros días. La constitución de las listas de candidatos para la renovación de los consejos directivos y decanos de las facultades, autorizada por el propio presidente de la nación en medio del caos que se vivía en la UNC, se convirtió en la oportunidad perfecta para que los estudiantes crearan alianzas con profesores reformistas y, aglutinados en la Federación Universitaria de Córdova (FUC) anteriormente Comité Pro reforma- participaran de la competencia electoral, apoyando al candidato que eligieron por unanimidad para dirigir el rectorado de la universidad. 9 El sector conservador hizo lo propio: conformó Centros Católicos de Estudiantes, que se articularon en una organización semipública llamada Corda Frates, y apoyó al candidato opositor ${ }^{10}$ a la reforma (Portantiero 1978; Romero 1998).

El «Grito de Córdoba» marcó un cambio paradigmático en la política universitaria del país y además de establecer el inicio de una demanda que subyace hoy por hoy bajo el rótulo de la lucha por la democratización, fijó unas prácticas

9 Enrique Martínez Paz, fue profesor de historia de la universidad y apoyó a los estudiantes reformistas convirtiéndose, por elección de éstos, en su candidato.

${ }^{10}$ Antonio Nores, de raigambre conservadora, aspirante al rectorado de la UNC. 
organizativas que paulatinamente se fueron convirtiendo en acervo de la cultura estudiantil y, a la postre, fueron permeadas por las fuerzas políticas nacionales. Los avances y retrocesos de sus principios se convirtieron en objeto de interés de los regímenes conservadores, y castrenses, que se han sucedido en el poder ejecutivo. La avanzada antagonista reaccionó y precipitó la contrarreforma en varias oportunidades: en 1922 toleró un movimiento antirreformista y, entre otros aspectos, ordenó la intervención y militarización de la UBA, de la UNC y de la Universidad Nacional del Litoral, creada hacía menos de tres años bajo la nueva legislación (Portantiero 1978). En 1930 se instaló abruptamente en el poder, asestando el primer quiebre constitucional de la República, con el apoyo, paradójicamente, de varios grupos estudiantiles que, al experimentar otra nueva intervención de las universidades, terminaron por sumar sus fuerzas a los grupos de filiación conservadora, de militancia católica, nacionalistas y antiliberales (Buchbinder 2005).

En un comienzo los grupos de universitarios que se organizaban -hoy agrupaciones estudiantiles- se autodenominaban partidos. Por ejemplo en la FFyL, la representación estudiantil estaba dominada por dos: el Partido Reforma Universitaria y el Partido Reformista. Estas formaciones no tenían diferencias ideológicas entre sí y ambas seguían los principios de la reforma. El primero mantuvo la representación de los estudiantes hasta 1937. En el periodo que se conoce como la «Década Infame»-que inicia en 1930 y termina 1943 con el siniestro que derrocó al presidente de turno- se crea el grupo «Insurrexit», disidente de la reforma e integrado por comunistas. Dicha agrupación, junto con el Partido Reformista de Izquierda, fue la primera en recibir orientación de cuadros marxistas y en avanzar rumbo a la politización de la vida universitaria (Buchbinder 1997). El fraude de los gobiernos en ese periodo no fue ajeno a la crítica estudiantil. Por esos años la detención de estudiantes se convirtió en un acto represivo común, junto a las luchas contra fuerzas nacionalistas de choque. Por ley se suprimió la agremiación del sector, inclusive en el nivel de educación secundario.

La protesta y la movilización de los estudiantes se transformaron progresivamente en objeto de la legislación estatal al vertiginoso ritmo de los procesos políticos que vivía el país. Con la asonada militar de 1943 se disolvió por decreto la FUA, las federaciones regionales y los centros de estudiantes. Las intervenciones concluyeron al año siguiente con el triunfo de los grupos desplazados. Sin embargo, en 1945, en respuesta a una ocupación estudiantil, el ejecutivo clausuró por varios días las universidades que a la fecha ya se caracterizaban por el activismo político de los universitarios: la de Córdoba, la Plata, Buenos Aires y el Litoral. En 1946 hubo una nueva intervención, en esa oportunidad se limitó la participación política del gremio y se promovió la persecución de todos los opositores al peronismo. Entrado el año 1947 el régimen derogó los principios reformistas, desarticuló las agrupaciones, y la actividad estudiantil contenciosa vivió un periodo de semiclandestinidad en el que las expresiones ligadas al reformismo tuvieron que ser subsumidas por las reivindicaciones de los primeros años, es decir, académicas.

Durante el resto de la década, las demandas se enfocaron en la denuncia de las condiciones edilicias, la falta de materiales, los contenidos de las carreras, los planes de estudio, las formas de enseñanza y en la supresión del examen de ingreso (Buchbinder 2005). Esta época se destaca además por la agencia de diferentes 
instituciones sociales: el control clerical de las casas de estudio, la purga sistemática de los opositores al gobierno de Perón, el espionaje y la represión directa sobre los estudiantes (Bonavena y Millán 2012).

\subsection{Politización y desmantelamiento}

Los años cincuenta, tanto en la Argentina como en la región, enmarcan el auge de las dictaduras y el recrudecimiento de la violencia, dos fenómenos sociales que impactaron de manera trascendental en la acción colectiva estudiantil. En 1951 la FUA se declaró en huelga general a raíz de los métodos de tortura a los que fue sometido un estudiante. En 1952 la policía clausuró los centros estudiantiles y los rectores fueron designados por el poder ejecutivo. En 1954 se ordenaron nuevas persecuciones contra los dirigentes de la FUA y se desató otra huelga que duró varios meses. «A excepción de una breve etapa del Partido Comunista, toda la militancia reformista fue opositora al peronismo desde sus inicios hasta la Revolución Libertadora, en 1955, cuando participó activamente de su derrocamiento» (Bonavena y Millán 2012, 109), atraída por la promesa de la autonomía universitaria. Con ese acto oficialmente se convirtió en «fuerza de agitación de los partidos políticos opositores» (Ceballos 1985, 16). En esta ocasión el hecho fue favorable a las ideas reformistas; en adelante los conflictos y demandas gremiales fueron signados por las disputas políticas nacionales, por la desperonización del Estado Nacional y por la aprobación de decretos que permitían la creación de universidades privadas con atribuciones para expedir títulos. En 1958 los estudiantes nuevamente hicieron noticia participando de la disputa entre la educación laica y libre, en respuesta a una declaración del ejecutivo sobre la libertad de enseñar (Califa 2004); la victoria del bando libre respaldado por la Iglesia Católica, por el empresariado y por el ejecutivo de ese momento histórico, afianzó la politización estudiantil y la radicalización de sus demandas en los años siguientes.

La protesta de los estudiantes argentinos, que en un principio se nutría de las ideas de José Martí y José Enrique Rodo, incorporó en estos años los discursos antimperialistas de la Revolución Cubana y las «Guerras de Independencia del Tercer Mundo» (Bonavena y Millán 2012). En los sesenta «aparecieron en la mayoría de las universidades agrupaciones políticas de estudiantes, y profesores, que se reconocían como peronistas» (Buchbinder 2005, 196-197) y tomó importancia una consigna latente en la actualidad, en eéste y otros Estados Latinoamericanos: la lucha por el presupuesto educativo. El golpe de Estado de 1962 insufló la actividad contenciosa de los universitarios y alentó el rechazo de la FUA. Hacia mediados de esa década la pugna por el poder político nacional se introducía agresivamente en la universidad y se expresaba a partir de una aguda lucha por el espacio físico de las instituciones; en la FFyL ocurría, por ejemplo, «a través de asambleas que, en más de una oportunidad, terminaban violentamente» (Buchbinder 1997, 215).

La persecución y represión sobrevino con la dictadura castrense de 1966. Durante el siniestro se suprimió el proyecto reformista literalmente a bastonazos ${ }^{11}$; se disolvieron las organizaciones estudiantiles, se prohibió la militancia, y el sistema

\footnotetext{
${ }^{11}$ Uno de los episodios de la represión el día del siniestro, 29 de junio de 1966, pasó a la historia como
} la Noche de los Bastones Largos. 
universitario argentino se organizó sobre bases institucionales autoritarias ${ }^{12}$. En consonancia con el Mayo Francés de 1968, la masacre de Tlatelolco y la nueva militancia obrera clasista nacional, en 1969 los estudiantes protagonizaron «un ascenso de masas en varias provincias, ocupando las primeras líneas de combate en acontecimientos como el Cordobazo, el Rosariazo, el Tucamanazo o el Viborazo» (Bonavena y Millán 2012, 110).

En los setentas, la presencia de los partidos políticos se hizo natural en la vida cotidiana universitaria y sus agrupaciones, algo así como sus brazos, en los términos que se refiere Buchbinder (2005), conformaban la vanguardia estudiantil, dominando su representación política. Se destacan, entre otras: la Juventud Universitaria Peronista (JUP), la FM del Partido Unión Cívica Radical, el Movimiento de Orientación Reformista (MOR) del Partido Comunista Argentino, y el Frente de Agrupaciones Universitarias de Izquierda (FAUDI) del partido revolucionario. Sus demandas desbordaron definitivamente el ámbito universitario. La violencia se constituyó en un "repertorio» (Tilly 2000) de rechazo político de muchos grupos juveniles; los debates teóricos y políticos marcaron el acercamiento ideológico del estudiantado al peronismo revolucionario, al comunismo revolucionario y la revolución armada. En consecuencia, las organizaciones apolíticas desaparecieron del horizonte universitario (Ceballos 1985) y sólo reaparecieron en el leve lapso democrático que antecedió el retorno de Perón en 1973 (Bonavena y Millán 2012). Su gestión y la de su viuda forzaron cambios sustanciales en el transcurrir nacional, incluido el de las casas de estudio: continuó su intervención, se implantó otro modelo autoritario y se reconoció la autonomía académica docente, al igual que la autarquía administrativa y económica, pero se prohibió terminantemente el activismo político.

Entre 1970 y 1976 los enfrentamientos sociales recrudecieron. Muchos jóvenes optaron por la lucha armada y fue incesante el accionar de organizaciones como la Alianza Anticomunista Argentina -grupo paramilitar de ultraderecha conocido como la Triple AAA - (Romero 1998), o el Comando Libertadores de América. En la dictadura de 1976-1983 los principios reformistas fueron socavados en su totalidad (Buchbinder y Marquina 2008). El régimen militar desmanteló todo tipo de organización que pusiera en riesgo su estabilidad. La organización continuó, pero despojada de los repertorios de confrontación y de las reivindicaciones políticas que cuestionaban el nefasto orden: la JUP, desestructurada políticamente, subsistió junto a agrupaciones como la FM o el MOR, los colectivos estudiantiles fueron reducidos a células que «actuaban en la clandestinidad», y la actividad de la FUA se limitó a cuestionar los índices de deserción y criticar las políticas educativas de la gestión militar (Romero, 1998).

Con la dictadura militar, distintas facciones de la clase dominante de nuestro país profundizaron la represión sobre la militancia de izquierda marxista y peronista. La universidad fue uno de los terrenos donde el terrorismo paraestatal y luego estatal de la burguesía se asentaría de manera privilegiada, como lo testimonia el hecho de que más del 20\% de los desaparecidos eran estudiantes universitarios. (Bonavena y Millán 2012, 110)

${ }^{12}$ La ley orgánica de las universidades nacionales $n^{0}$ 17.245/67 prohibía en el artículo 10 toda forma de propaganda, proselitismo agitación o adoctrinamiento de carácter político. 


\subsection{Resurgimiento}

La reorganización de los centros y agrupaciones estudiantiles se inició, de manera gradual, en la década del ochenta con la transición democrática. En 1982 fue tolerada nuevamente en las universidades y en 1983 fue normalizada con la restitución de los principios que evocaban el modelo reformista de 1918 (Chiroleu et al. 2012). El proceso político posibilitó la reorganización de formaciones partidarias (Buchbinder 2005) y el surgimiento de organizaciones identificadas como independientes o autónomas, por mantenerse al margen de la lógica de los partidos (Arriondo 2011). Unas y otras retomaron las consignas construidas en el marco del pensamiento revolucionario de las décadas anteriores (marxista, leninista, trotskista, maoísta, etc.). El incremento de las últimas adquirió fuerza a finales de ese decenio:

Las agrupaciones independientes, funcionaron en aquel contexto como nuevos espacios de politización que, por un lado, sirvieron como refugio para militantes partidarios desencantados que no encontraban un lugar en las estructuras políticas clásicas y, por otro, se constituyeron en espacios de creatividad y experimentación de nuevas prácticas y formas de organización políticas. (Picotto y Vommaro 2010, 150)

Las causas de su inestabilidad se atribuyen principalmente a las dictaduras, al terrorismo y a las vicisitudes que implica la politización (Portantiero 1978; Ceballos 1985; Buchbinder 1997 y 2005; Romero 1998). La proliferación de organizaciones en las distintas universidades nacionales se aduce por el avance del neoliberalismo de los noventa, junto con la crisis económica y la crisis de representación política, que golpeaba fuertemente a la nación a las puertas del siglo XXI (Picotto y Vommaro 2010; Arriondo 2011; Liaudat et al. 2012).

Las elecciones que se realizan en las casas de estudio desde el retorno a la democracia generan una disputa similar a la que adelantan los partidos políticos por detentar el poder del Estado, la cual se desarrolla en el interior de los claustros y expone uno de los principales obstáculos para la unidad del estudiantado, dada la división ideológica que causa. Por lo tanto las coaliciones y alianzas entre agrupaciones suelen ser frecuentes mientras que la administración de los centros de estudiantes, la representación del demos y la dirección de las federaciones que los nuclean, suelen ser ostentadas por las organizaciones instituidas; un caso evidente es el de la FM que ha dirigido a la FUA desde la transición democrática y, renovada bajo la denominación «Nuevo Espacio»13, continua disputando el control de varios claustros con sectores de izquierda, coaligados en el «Frente Reformista», que tienen un porcentaje de la conducción nacional.

Con la consolidación de la política universitaria de la UCR se fue imponiendo un mecanismo electoral para escoger autoridades en las organizaciones corporativas (como los centros de estudiantes y federaciones) y en los cuerpos de gestión académica, lo que favoreció un perfil de estudiante que delega sus intereses en un representante, transformándose ésta en la forma preponderante de participación. (Bonavena y Millán 2012, 111)

${ }^{13}$ Nuevo Espacio es el nombre que adoptó a Franja Morada después de la caída del gobierno de De la Rúa en el 2001, cuando perdió la FUBA. 


\subsection{Demandas y disputas recientes}

La protesta estudiantil se muestra siempre atravesada «por procesos de transmisión política intergeneracional, que expresan el vínculo estrecho entre las agrupaciones estudiantiles, partidos y movimientos políticos, que persisten en la escena pública a lo largo del tiempo» (Carli 2014, 12). En todos sus episodios las demandas y disputas giran en torno a un componente fenomenológico que en la Teoría de la Movilización de Recursos se conoce como la Estructura de Oportunidades Políticas: «dimensiones consecuentes», no necesariamente formales o permanentes, del ámbito político, que proporcionan incentivos para la movilización del estudiantado (Tarrow 1999, 2004). Sin ella su causa carece de todo sentido y posibilidad.

Los descontentos -escribe Sidney Tarrow- encuentran oportunidades favorables para reclamar sus demandas cuando se abre el acceso institucional, cuando emergen conflictos entre las elites, cuando pueden conseguir alianzas y disminuye la capacidad represora del Estado. Cuando todo esto se combina con una percepción elevada de los costes que supondría la inacción, las oportunidades dan lugar a episodios de acción colectiva. (Tarrow 2004, 109, 110)

Al ritmo del acontecer político se motorizan las demandas, éstas son más frecuentes que la movilización. Lo que varía de la acción en el tiempo es el nivel y tipo de incongruencias que sus enunciantes experimentan, es decir, «las restricciones a su libertad de acción y las amenazas que perciben sobre sus intereses y valores» (Tarrow 2004, 109). Con el retorno a la democracia los universitarios reclamaron el pleno ejercicio democrático, la expulsión de los funcionarios que habían servido a la dictadura, el ingreso irrestricto a la universidad y se movilizaron exigiendo justicia por la violación de derechos humanos cometida durante el fatídico episodio (Liaudat et al. 2012). En los años noventa lo hicieron en el marco de la publicación del documento Bulit Goñi ${ }^{14}$ y las reformas del menemismo, en especial la Ley Federal de Educación, y la Ley de Educación Superior (LES). Esta última alimentó la consigna «la LES no pasará» y el «abrazo al Congreso», táctica que, sin lograr su objetivo, buscaba crear un cordón humano alrededor del recinto para evitar el ingreso de los diputados y la aprobación de la legislación (Bonavena y Millán 2012). Durante el segundo lustro de la década, los estudiantes formaron un bloque de contención gremial en contra del arancelamiento, la evaluación y los recortes presupuestarios (Krotsch 2014).

La recesión económica que comenzó en 1998 incentivó su participación en las protestas de 1999, 2000 y 2001 (Buchbinder 2005). Por esos años se sumaron a las luchas de los ahorristas, de piqueteros y desocupados, de recuperación de fábricas y de vecinos (Liaudat et al. 2012). La LES, desde su sanción, se convirtió en un dispositivo de rechazo permanente. Junto a ella se retomaron las demandas reformistas alusivas a la autonomía universitaria, en particular la participación política estudiantil en su gobierno. La falta de voluntad para democratizar las universidades ha amparado una lectura antirreformista «ya no de raíces católicas sino conservadoras de las posiciones académicas y económicas» (Bonavena y Millán

${ }^{14}$ El texto interpela la distribución constitucional de las competencias tributarias en la Argentina. 
2012, 114). Las expresiones de esta pugna se repiten con cierta frecuencia en buena parte de las universidades estatales, bajo la consigna de la lucha por la democratización: en la UBA, la Universidad de Comahue, la Universidad de la Patagonia, la Universidad Nacional de la Plata, la Universidad de Rosario, la Universidad Nacional de Córdoba y la Universidad de Mar del Plata (Liaudat et al. 2012; Bonavena y Millán 2012).

Desde el 2015, el desmanejo de la economía, cíclico en la sociedad Argentina, alienta la protesta estudiantil, y articula a la comunidad universitaria con otros sectores sociales. En la actualidad los estudiantes vienen participando de acciones de confrontación y movilizaciones, contra el recorte presupuestario propuesto por el gobierno nacional, para las 57 universidades públicas del país (Salas 2018). Recientemente se realizó «la marcha en defensa de la universidad pública» en las principales ciudades de las provincias. El evento reunió a todos los miembros de la comunidad educativa y científica, en reclamo por salarios dignos y en rechazo al ajuste, y culminó con una enorme concentración en Buenos Aires (Bullentini 2018.) La contienda ha sido liderada por los docentes y ha incluido la toma de claustros, volanteadas, huelgas, marchas actividades callejeras como clases públicas, elaboración de murales y abrazos simbólicos a las sedes; a la fecha -septiembre de 2018- el conflicto suma algo más de cuatro semanas y las tomas de las facultades no cesan.

\section{Recursos de la organización}

En sincronía con la optimización de las oportunidades políticas, en cada episodio de confrontación se suelen desarrollar los mismos procesos, independiente de que adquieran o no un carácter masivo. Sin el interés de agotarlos, señalo cinco: 1. Los enmarcados o esquemas de interpretación crítica del contexto social (Snow y Benford 2006). 2. La producción y la difusión de información respecto a la realidad de ese contexto (Melucci 1999), el Manifiesto Liminar, citado en el encabezado, es un ejemplo de ello. 3. La creación de organismos federativos como la FUC o la FUA y el trabajo articulado de organizaciones o redes (Melucci 1999). 4. La unidad con otros sectores como el sindicalismo obrero (McCarthy 1999) y 5. La puesta en marcha de toda una serie de prácticas y tácticas movimientistas; verbigracia, manifestaciones en las calles, motines o tomas de instalaciones (Tilly 2000).

La organización es fundamental en todos y cumple un papel determinante en las protestas, a través de las agrupaciones. El número de estas últimas varía en cada facultad y una buena parte tiene presencia en varias universidades del país. A las elecciones para Centros de Estudiantes y Consejo Directivo por el Claustro Estudiantil de la UBA, llevadas a cabo en septiembre de 2017, se presentaron más de sesenta $^{15}$ en las trece facultades que la componen ${ }^{16}$ (Juventud Informada 2017; La Izquierda Diario 2017), doce lo hicieron en más de una a la vez, por ejemplo: la agrupación Movimiento Universitario Sur (SUR), La Corriente Estudiantil Popular Antiimperialista (CEPA), Nuevo Espacio, La Mella y el Partido Obrero (PO).

\footnotetext{
15 Ver listado completo en Anexo, Cuadro 2.

16 Facultad de Filosofía y Letras; Facultad de Ciencias Sociales; Facultad de Derecho; Facultad de Ciencias Económicas; Facultad de Arquitectura, Diseño y Urbanismo; Facultad de Psicología; Facultad de Medicina; Facultad de Ciencias Exactas; Facultad de Agronomía; Facultad de Ingeniería; Facultad de Ciencias Veterinarias; Facultad de Farmacia y Bioquímica; Facultad de Odontología.
} 
La emergencia de las organizaciones actuales es reciente y está asociada a hechos coyunturales, verbigracia, las agrupaciones Izquierda Socialista y SUR, creadas en 2006 y CAUCE, creada en 2010. En algunos casos es el resultado de rupturas entre organizaciones previamente conformadas, en muchos su existencia es volátil, hecho que se explica por el desgaste de la organización o por la partida de la universidad de los estudiantes que las fundan. Si se compara el número de las agrupaciones que vienen participando, tan sólo en las actividades electorales de los dos últimos periodos es posible percatarse del aumento o la disminución de aquellas que realizan actividades durante periodos cortos, y de la prevalencia de las agrupaciones que se adscriben a organizaciones consolidadas como los partidos políticos. Así, mientras que en 2013 en la FFyL existían alrededor de 30, en 2017 no sobrepasaron las 2017; la agrupación UNG, que surgió en 2005 de la ruptura de la Corriente Estudiantil de Liberación, se disolvió en 2014. En otros casos el surgimiento de estos grupos ha sido orquestado por el propio Estado, un ejemplo es la agrupación Movimiento Universitario Evita (MUE), conformada por el régimen Kirchner en 2009; otro la agrupación Cambiemos, estructurada en 2015 por el gobierno actual.

Todas tienen semejanzas pese a que sean distintas: a) sus integrantes comparten ideas y constructos respecto a su realidad inmediata; b) sus «acciones», y bajo ciertas circunstancias sus fines, trazan un puente que las acerca aun cuando los principios que siguen las distancian; y c) operan reproduciendo las mismas dinámicas de acción. Estos patrones facilitan la distinción de varios recursos que intervienen en la constitución y lógica de la protesta, componen un todo con significado, y se repiten en cada agrupación. A continuación menciono siete: los estudiantes, la ideología, la identidad, los objetivos, las demandas, las estrategias y los medios de difusión.

\subsection{Estudiantes}

Las agrupaciones suelen tener dos figuras de integrantes: aquellos que ejecutan los procesos de formación de la acción colectiva, reconocidos en el argot de la movilización como activistas o militantes, es decir los que integran y participan de forma activa en una organización política (Quirós 2014); y quienes participan de forma irregular. Aquí se hace referencia a los primeros cada vez que se alude a los estudiantes. Una de las transformaciones que expresa este sector social en el tiempo es la presencia y participación de las mujeres. En consecuencia, la lucha del estudiantado universitario se ha nutrido también de la causa feminista.

Ellos y ellas materializan su acción porque son capaces de articular y difundir discursos sobre cuestiones controvertidas de la vida social, influyendo en las formas de ver la realidad compartida por sus públicos. Adquieren la capacidad de ejecutar los procesos que la protesta implica porque se asumen como sujetos/sujetas políticos en la búsqueda de las condiciones que les permiten ser actores de su propia historia y como portadores de una ética elevada que les posibilita ser los representantes tanto de sus congéneres como de los sectores sociales que consideran en desventaja (Albornoz 1971; Touraine 1987 y 1997; Melucci 1994 y 1999; Laraña 1999).

$\mathrm{Su}$ origen social es diverso. Antaño se ha reconocido su pertenencia a las clases emergentes o en ascenso socioeconómico (Portantiero 1978), sin embargo en las movilizaciones actuales se destaca la participación de la primera generación de

\footnotetext{
17 Ver listados completos en cuadros 1 y 2 del Anexo.
} 
universitarios que provienen de sectores con bajos ingresos económicos (Salas 2018). La proporción de integrantes por cada agrupación varía en cada facultad, tanto como la cantidad de éstas. Generalmente es menor de 6, cuando supera ese número no sobrepasa los 15, y llega a alcanzar más de 30 sólo bajo ciertas condiciones y circunstancias. Esta situación se presenta en las agrupaciones que hacen presencia en varias facultades y universidades adscritas a partidos políticos tradicionales como el Obrero, y que constituyen frentes para alcanzar espacios de poder como los centros de estudiantes.

La formación política de quienes militan tiene una estrecha relación con los procesos de politización que se conciben con anterioridad en espacios de interacción como el núcleo familiar, se suele potencializar en el entorno social y adquiere su realización en la vida cotidiana universitaria. Un integrante del Movimiento Universitario Sur al respecto señaló lo siguiente:

Yo digamos empecé a militar ya a los 24 años, o sea ya tenía una conciencia política formada. Desde chico, mis viejos me fueron formando políticamente. Tenía una idea cerrada, más o menos de cuáles eran mis ideales políticos [...] así que no tuve la necesidad de participar en otros movimientos porque éste era acorde a lo que yo buscaba.

Sus primeras experiencias de activismo político suelen ocurrir en la secundaria y a menudo son el producto de la persuasión. Esta situación la reconocieron la mayoría de los entrevistados, situación que no es de extrañar si se tiene presente la tradición movimientista que posee el país. Destaco dos testimonios, el primero pertenece a una integrante de la agrupación Izquierda Socialista, el segundo a uno de la agrupación USG:

Desde chica me interesaban los movimientos sociales, en el secundario, empecé a buscar dónde militar. Tenía un grupo de amigas -a uno cuando es adolescente lo influyen bastante- que querían hacer lo mismo que yo; entonces juntas buscamos un lugar dónde militar. Yo iba a un colegio privado en el secundario, entonces no había un espacio de organización en ese marco, así que espere a entrar a la carrera. Mi elección de la UBA fue totalmente política, la UBA es un espacio para hacer política. Quizás también por una cuestión de familia siempre estuve muy influenciada por la izquierda, mi papá fue militante de la corriente a la que pertenece mi partido, y entonces bueno...

Mi primo milita en una universidad de la Patagonia, en mi familia hay muchos militantes de distinta índole, entonces la discusión siempre estuvo presente. Cuando llegué a la facultad, yo quería participar activamente en la política de forma orgánica, entonces discutí con muchas agrupaciones, presuponiendo que con la que más afinidad iba a tener sería USG porque había discusiones que yo ya tenía con mi primo. Mis valores estaban más del lado de la propuesta que me hacía esta agrupación donde existe una raigambre muy fuerte entre el hacer y decir. Mi voz encontró un proyecto político con el que se identificó.

Su tiempo lo suelen repartir entre los cursos, el «laburo», en el caso de quienes se emplean, y en las acciones que su militancia requiere. Se forman académicamente en distintas disciplinas, atraviesan diferentes periodos de éstas, y algunos cursan 
Ciclo Básico Común para el ingreso a la universidad. El carácter transitorio de su condición juvenil los convierte en un sector diferenciado, en relación con otros grupos etarios, que posee cierto margen de libertad y los excluye de los compromisos que se adquieren en la adultez, privilegiándolos para tomar posiciones ideológicas, y revelarse en contra de formas que consideran autoritarias con mínimos riesgos personales. Esa misma condición produce en ellos una búsqueda permanente de identidad que los lleva a rechazar los valores inculcados por las viejas generaciones, a preocuparse por cuestiones ideales, a ser permeables a la desilusión social, sensibles a los llamados a la lucha, a la unidad, a sumarse a las causas de los sectores oprimidos, y a atribuirse la misión de construir un mundo nuevo e igualitario (Albornoz 1971; Touraine 1997).

Los educandos encuentran en la acción colectiva su fortín para enfrentarse a las adversidades y lo convierten en espacios de libertad. Su actividad, en pocas palabras, alimenta su alegría de vivir (Touraine 1997; Laraña 1999; Zibechi 2003). Las respuestas a la pregunta sobre la satisfacción de militar develan gozos que abarcan desde el plano político, social e intelectual, hasta el sexual. Cito dos más; la primera corresponde a un integrante de la agrupación CAUCE la segunda a uno de la agrupación SUR.

El aporte y pertenecer a un proyecto colectivo es realmente un cambio cualitativo en la vida de cualquier persona, sea el proyecto colectivo del tipo que fuera, cuando implica una entrega importante desde la propia subjetividad, más aún, cuando el proyecto apunta a transformar la vida de las personas en un sentido de mayor libertad, de mayor creatividad, de mayor desarrollo personal y social.

Despertarme todos los días sabiendo que estoy haciendo algo por cambiar la realidad de mi país, esa es la satisfacción máxima. Nosotros como Movimiento Universitario Sur participamos del movimiento Libres del Sur, tenemos una compañera diputada, participamos del frente amplio progresista, y sabemos que estamos disputando con los sectores más poderosos de la política y de la economía; que le estamos disputando el poder y que queremos llegar a ser gobierno para, desde el Estado, desplegar todas las políticas necesarias para redistribuir realmente la riqueza y para hacer una patria más justa, soberana, e igualitaria. Todos los días me levanto pensando en eso, así que estoy plenamente satisfecho.

\subsection{Ideología}

La ideología, entendida como el sistema de creencias, ideas y valores que sirven para justificar la oposición a un orden político determinado (Zald 1999), expresa los ideales y principios que guían las acciones estudiantiles. Opera como subproceso, de un proceso mayor denominado formación del consenso, y depende de las oportunidades coyunturales que ofrece el contexto social (Melucci 1999).

Los estudiantes asumen una adscripción ideológica con la cual construyen criterios amplios para llegar un público mayor e interpelan sistemas de creencias, elaborados por diversos actores sociales, en el discurso organizado que difunden. En sus organizaciones persisten las ideologías retomadas en los años ochenta. En algunas agrupaciones se encuentran plasmadas en el nombre, caso Izquierda Socialista, agrupación MUE, o agrupación PSTU. En las agrupaciones independientes la orientación ideológica es compuesta: es el caso FER cuyos 
integrantes se vinculan con el socialismo, comunismo, anarquismo; varias se adscriben al guevarismo, y la mayoría retoman las distintas variantes del marxismo (Cortés y Kandel 2002). Así, se puede hallar en este escenario una suerte ideológica de marxismo, leninismo, trotskismo, guevarismo, en ocasiones carente del rigor que caracterizó a estas corrientes en su época, mezclada con doctrinas endémicas de Argentina -clásicas como el peronismo y sus vertientes, o contemporáneas como el kirchnerismo o el macrismo- hoy por hoy, matizadas de los principios de la epistemología feminista e inmersas en la lógica partidaria que subsiste en las facultades.

\subsection{Identidad}

El componente identitario equivale a un incentivo para la protesta: «construye el sistema de acción (las expectativas y las posibilidades y límites de la acción) en el cual un individuo se define a sí mismo y a su ambiente» (Revilla 1994, 9).$^{18}$ Sin embargo, representa un factor «ambiguo» para las agrupaciones, hecho visible en el dualismo independientes/partidarias, pues mientras motoriza la acción colectiva arraiga el sectarismo entre ellas (Melucci 1999). Los estudiantes producen su identidad a partir de símbolos cuya carga emocional potencia la movilización voluntaria en escenarios de conflicto. Todos dependen del contexto y le dan un toque sarcástico a las circunstancias que desean denunciar. El potencial de este recurso se basa en la relación de correspondencia entre el signo que difunde y la realidad a la que alude, por ejemplo elaborando caricaturas de algún personaje que identifican como enemigo, o construyendo objetos alusivos que presentan en sus actos públicos; en la actualidad, a propósito del recorte presupuestario, es común ver tijeras gigantes en las marchas.

Este recurso y la simbología de la protesta estudiantil se caracterizan, entre otras cosas, por estar en el origen del sentimiento de pertenencia a un grupo diferenciado, por relacionarse íntimamente con la imagen que los integrantes de cada organización tienen de sí mismos, así como con el sentido de su existencia individual, y por contener expresiones propias tanto del pensamiento asociado a la «izquierda política» como del asociado al oficialismo. Además delinea el horizonte de los sistemas de pensamiento de las agrupaciones, proyecta los rasgos colectivos, cumple un rol relevante en la producción de la razón de la movilización, y es parte de la herencia ideológica y cultural de la sociedad. Las luchas sociales históricas han acuñado la mayoría (personajes, creencias, colores, frases célebres, cantos, etc.).

\subsection{Objetivos}

Los objetivos que guían cada organización son diversos, siguen el hilo de sus ideologías y están determinados por la percepción que tienen los estudiantes de su entorno, es decir, los construyen, hacen elecciones y toman decisiones de acuerdo con la realidad y las expectativas socialmente construidas (Revilla 1994). El sector expresa dos modelos: los que desbordan el ámbito universitario y los gremiales. Ambos, en sentido tácito, son instrumentales a su acción colectiva. Los primeros trazan un margen diferencial entre las dos formas de organización. Las agrupaciones partidarias proyectan sus horizontes incluyendo a otros sectores, alimentan la idea

18 Paréntesis de la autora. 
del cambio social, y tienden a retomar las consignas de organizaciones tradicionales como los sindicatos de trabajadores. Así se destaca el caso de la agrupación perteneciente al Partido Obrero, cuyo objetivo central es hacer la revolución de la clase obrera; el caso de la agrupación Prisma y el MUE cuyo objetivo es luchar por una Universidad pública y de calidad al servicio de los trabajadores en la primera, y del pueblo en la segunda; y el caso de La Mella que enarbola la transformación profunda de la sociedad.

Los objetivos gremiales son esgrimidos tanto por las agrupaciones partidarias como por las independientes: pretenden «bienes públicos» puntuales y disponibles a todos los miembros activos y potenciales de la organización, contemplan la liberación, y generalmente concentran intereses académicos idénticos, expresados en diferentes términos. Por ejemplo: construir una Universidad para la transformación social; trabajar por los derechos de los estudiantes; luchar por una educación pública, gratuita y de calidad; transformar la realidad social dentro de cada facultad, conservar los privilegios obtenidos a los largo de la lucha (tarifa estudiantil en el transporte público, los comedores estudiantiles, etc.).

Los propósitos de la organización estudiantil son instrumentales en sentido tácito porque, aun cuando no lo expresan puntualmente, están orientados a incrementar los recursos para defender los intereses de las agrupaciones. En otras palabras, hacen las veces de «bienes e incentivos públicos»(Olson 1992) que apuntan a acrecentar el número de integrantes mientras avanzan tras los fines que fundamentan la organización. Todos indistintamente expresan el propósito que motoriza sus acciones: «mantener encendida la protesta social en sus diversas manifestaciones» (Biagini 200ob, 28), independiente de que la lucha se encuentre fragmentada y de que no logre alcanzar el mismo impacto ni la eficacia que obtuvieron las generaciones estudiantiles otrora. Un estudiante expresó lo siguiente al respecto:

Independientemente de si se gana o se pierde la lucha yo necesito juntar gente, cuando nos quejamos aisladamente nuestras voces suenan menos fuerte, por eso soy partidario de la organización.

\subsection{Demandas}

Las demandas representan los componentes lingüísticos que expresan los significados y signos de la protesta. Éstas se caracterizan por diversas razones: expresan intereses que aluden al bienestar universitario, al carácter público de la educación y a aspectos políticos de la vida nacional; señalan a grupos cuyas acciones afectan al conjunto de la sociedad; se complementan entre unas y otras; se orientan al cambio social (Raschke 1994; Munck 1995); y aluden problemáticas referentes a la violencia de género, aspecto novedoso en la movilización del gremio universitario.

Al igual que con los objetivos expresan dos modelos: por una parte se destacan las que se relacionan con el bienestar y pasan por la oportunidad de becas así como por la creación de políticas de acceso y permanencia; por otra parte sobresalen las que aluden diversas problemáticas sociales $\mathrm{y}$, por lo mismo, son mucho más elaboradas, por ejemplo: las que de manera explícita pretenden el incremento del presupuesto para la educación y la ciencia, salario digno para los docentes, balances públicos de los centros de estudiantes, la construcción de una Universidad al servicio de los trabajadores; calidad de vida para la clase obrera, etc. Las reivindicaciones de 
género denuncian feminicidios y se suman a campañas como «Ni Una Menos» o la legalización del aborto.

Con estos recursos se mantiene latente la causa estudiantil y se identifican los adversarios de su lucha. Además de funcionar como artefactos de contención y problematización repelen directamente: el neoliberalismo; la Ley de Educación Superior; la Comisión Nacional de Evaluación Universitaria (CONEAU); el saqueo imperialista; los ajustes presupuestales a la educación pública y al nivel de vida de la clase obrera; los procesos antidemocráticos; las formas de elección de las autoridades universitarias; la marginación de la clase baja en los proyectos políticos estatales; la mercantilización de la educación; la explotación; la opresión; la violencia sexual, las problemáticas de género, etc.

\subsection{Estrategias}

Las organizaciones estudiantiles no tienen una forma de actuar sino formas de acción consensuada con las cuales llevan a cabo sus protestas. En la sociología de los movimientos sociales se les conoce como «estrategias» o «repertorios de confrontación» (McCarthy 1999; Tilly 2000), éstas, al igual que los demás recursos mencionados, hacen parte del plus de aprendizajes que se ha configurado en las luchas estudiantiles presididas por las generaciones anteriores. Dicho en otros términos, son la praxis de la acumulación de conocimientos esculpidos en campañas, que hoy hacen parte de la historia y del conjunto de prácticas y símbolos compartidos por la sociedad argentina. Son usuales: las asambleas; los encuentros estudiantiles; los círculos de estudio; las cátedras libres; los cortes de calle; las marchas; las charlas; las tomas de las facultades, de los rectorados; la difusión de sus propósitos aula por aula, estudiante por estudiante; las movilizaciones al consejo directivo; los acampes; los mesazos; los abrazos a recintos; los festivales; las actividades de educación popular y los talleres de género. La participación multisectorial es una estrategia extraordinaria que tiene lugar cuando son vulnerados los intereses de diferentes sectores, como ocurre en la actualidad en el marco de la lucha por la educación pública. Todas se ponen en práctica según el contexto y el proceso político.

\subsection{Medios de difusión}

Los medios de difusión son imprescindibles para movilizar la causa. Ideologías, identidades, símbolos, objetivos y demandas, son plasmados en ellos con el fin de crear en el estudiantado, y en el público en general, una conciencia homogénea respecto de las problemáticas abordadas. Los espacios físicos son tradicionales; en las facultades cada organización se ha hecho uno desde el cual opera e insemina sus ideales. Algunas lo hacen en locales propios dentro de los claustros como la FM, otras se valen de escritorios o mesas que forman en los pasillos convirtiéndolos en su despacho, o como dicen los mismos estudiantes, en «punto de información» dentro de la facultad.

El periódico es una herramienta con la que cuentan particularmente las agrupaciones partidarias; en general todas hacen uso de pequeñas cartillas y otros impresos que las generaciones estudiantiles de antaño, y la protesta social desde el siglo XVIII, utilizaron para difundir sus ideales, anunciar sus actividades, evaluarlas e informar de sus éxitos o fracasos: revistas, folletos, panfletos, volantes, grafitis, etc. 
(Tilly y Wood 2010). Pese al transcurrir de los años, este medio continúa siendo un mecanismo eficaz para atraer participantes - en la contienda del «Grito de Córdoba» los estudiantes editaron la Gaceta Universitaria para difundir sus ideas y propósitos-. A la pregunta por la sumatoria de compañeros a la causa, un estudiante de la formación del Partido Obrero respondió lo siguiente

¿El tema del reclutamiento?, nosotros le decimos reclutamiento. Nosotros siempre lo hacemos de una forma política, no tenemos los intereses de decir que somos los mejores amigos, tenemos una relación política hacia todo el mundo, después obviamente se conforman amistades, pero lo que hacemos es construir una orientación política bien marcada para explicarla a todo el mundo. Lo primero que hacemos, «como el partido bolchevique» -je-, es tener siempre a mano nuestra prensa, nuestro periódico (tenemos un periódico semanal, que sale todos los jueves); siempre en la mano o en la mochila el periódico para cualquier persona, con la que se dé una discusión política, ofrecérselo. El periódico es nuestro lineamiento político que discutimos con todo el mundo: imira está es la posición del partido obrero!; y entonces empezamos a discutirlo, eso es básico. A partir de ahí, nosotros hacemos actividades todos los días, hacemos cosas, venimos movilizamos, vamos allá, ponemos una mesita en la esquina. Tratamos de llevar a la gente a la práctica, a militar, a sumarse, pasamos por las aulas. Ese es el modo, no tiene muchas más trabas.

Las nuevas tecnologías de información y comunicación (NTIC) representan otra de las novedades de la protesta estudiantil en nuestros días no sólo en la Argentina. Éstas reducen los costos y superan la unidireccionalidad de los medios de comunicación tradicionales, ya que en ellos el contenido se envía de uno a muchos mientras que con aquéllas se establece cierta interacción entre emisores y receptores. Apelando a Sadaba y Roig (2004), podemos decir que desarrollan tres funciones fundamentales para la protesta de este sector: la primera es la de informar. Esta práctica tiene lugar mediante páginas web propias y aquellos portales no convencionales de noticias que plantean temáticas relacionadas con los intereses de los estudiantes. También se desarrolla a través espacios de publicación abierta -que superan el modelo «unidireccional» emisor-receptor permitiendo al «informado» convertirse además en el «informante» que emite su propia versión u opinión de la información a la que accede- como weblogs, y de redes sociales como Facebook, Twitter, WhatsApp o del correo electrónico. La segunda función se relaciona con la coordinación de los recursos que permiten el funcionamiento colectivo de las agrupaciones; y la tercera con la producción del sentido e identidad pues permiten el acercamiento, la difusión de las demandas y el conocimiento mutuo entre los estudiantes y los simpatizantes que se interesan en participar de su causa.

\section{Lógica de la cuestión}

Los procesos inherentes a la acción colectiva estudiantil conllevan sinergias que se nutren del acervo cultural, esto es del cúmulo de símbolos y prácticas compartidos por los grupos sociales (Zald 1999), mientras robustecen, en simultáneo generación tras generación, la ideología, la identidad y la persistencia de la protesta. En el cenit del fenómeno pueden aparecer como fortuitos pero en realidad se desarrollan como 
una frecuencia de pasos «dándose», que tienen una continuidad y se realizan en el tiempo (Zemelman 2009). Algunos requieren un esfuerzo particularmente cognoscitivo por tratarse de actividades en las que predomina el uso del intelecto; otros son más bien operativos por tratarse de la puesta en funcionamiento de las tácticas y de los mecanismos de persuasión que los estudiantes tienen a su alcance.

Aunque unos y otros se complementan, ambos son diferenciales pues se fortifican entre sí, a la vez implican actividades de una y otra índole, retroalimentan el formato organizativo de cada agrupación y pretenden la movilización masiva del público. Mientras que los procesos cognoscitivos se basan en la consolidación del consenso colectivo, en el diseño de la protesta y en la justificación de la masificación; los operativos implican la conjugación de los medios, la difusión del consenso y la ejecución del método para materializar la unidad. Los procesos cognoscitivos se manifiestan propiamente en las acciones encaminadas a problematizar la realidad (ejemplo: construir definiciones colectivas, identificar injusticias, señalar responsables, elaborar demandas, proponer objetivos, etc.), los procesos operativos se revelan en los planes y los instrumentos para intervenir en esa realidad (ejemplo: difundir sus causas, confrontar la política universitaria, develar conflictos, etc.). De acuerdo con las perspectivas teóricas que guían este análisis, aquéllos se refieren a los procesos de creación de «marcos» o «enmarcado» (Zald 1999; Tarrow 2004; Snow y Benford 2006) y a la construcción de la identidad colectiva (Melucci 1999); los últimos a las «estrategias de movilización» (Tilly 2000) y a los «ciclos de acción» (Tarrow 2004). Pensados como dimensiones de la protesta se pueden explicar siguiendo el modelo cultural de la «oratoria» y el «drama» (Gusfield 2014).

\subsection{Dimensión retórica}

La retórica entendida como el arte de persuasión, o «como la facultad de observar, en cualquier caso dado, aquéllo que es apto para persuadir» (Aristóteles, como se citó en Gusfield 2014, 95), toma sus recursos de los hechos del lenguaje o de lo que bien se puede asumir como "gramáticas de la vida pública»; esto es, del conjunto de signos y reglas para hablar que adquieren sentido en un espacio específico (Cefaï 2008). Se expresa en las técnicas discursivas, cobra razón en un contexto de prácticas e instituciones compartidas fuera del cual perdería toda lógica, y depende de la capacidad de los estudiantes tanto para ajustarlas a la especificidad de sus demandas como para valerse de ellas y emocionar a su público (Cefaï 2014). Además de ello enuncia el recurso ideológico y arraiga la identidad, plasmada en el enmarcado, esto es, en el «esquema interpretativo que simplifica y condensa el mundo que está ahí fuera puntuando y codificando selectivamente objetos, situaciones, acontecimientos, experiencias y secuencias de acciones en el pasado y presente de cada individuo» (Snow y Benford 2006, 125).

Este dispositivo explica la vía mediante la cual se canalizan las oportunidades políticas. Al develar el carácter «injusto» de situaciones que generalmente son percibidas como habituales o normativas permite sugerir alternativas para superarlas (Tarrow 2004; Zald 1999). El proceso se repite en cada una de las luchas del gremio. La que amerita la demanda de la democratización lo expresa claramente, dado que se ha convertido en una contienda frecuente en los últimos años: los estudiantes evalúan el porcentaje de su participación en la elección del rector y se reconocen como mayoría, frente a una normativa que determina directamente su 
paso por la universidad. Por lo tanto, asumen que tienen la prelación en los comicios y develan públicamente su desventaja representativa, connotándola de atropello.

El preámbulo de cada certamen electoral de rectores y decanos universitarios se acompaña con un conjunto de marcos en contra de su realización. Para la agrupación del Partido de los Trabajadores Socialistas (PTS) «la Universidad sigue siendo gobernada por una casta divina de los profesores titulares; el voto de un docente vale en algunos casos igual que el de 135 estudiantes; en filo 200 profesores eligen a 8 representantes, 1,800 graduados eligen a 4 y 9,700 estudiantes a 4 más». De acuerdo con la formulación de la agrupación adscrita al Partido Socialista de los Trabajadores Unificados (PSTU) «en la UBA, las elecciones de rector están respaldadas por el Consejo Superior, donde los docentes tienen 19 votos, los 360,000 estudiantes sólo tenemos 5 y los 12,000 trabajadores auxiliares no votan». En la opinión de la agrupación CAUCE el «esquema garantiza la sistemática conservación de las decisiones en las mismas manos, que se eligen a sí mismas y sancionan la continuidad de las políticas académicas». Para la agrupación USG «la democratización no es un problema que deviene cada tanto, sino una realidad que todos los días atraviesa a los más de 300 mil estudiantes de la casa de estudios bonaerense».

La construcción de todos estos esquemas implica tres procesos: el «diagnostico», el «pronóstico» y la «motivación», esenciales para la configuración de las creencias y los significados de la protesta, que se basan en la elaboración de una lectura crítica de la situación, en la formulación de soluciones a esa situación, y en la invitación a transformarla en pro del beneficio común (Snow y Benford 2006). El primero involucra la identificación del problema, los alcances de éste y la atribución del agente o los agentes causales; el segundo además de sugerir las soluciones implica trazar los objetivos y definir las maniobras de la acción; y el tercero está confinado a la elaboración de argumentos que sirvan como acicate para la movilización.

En el proceso de diagnóstico los universitarios emplean adjetivos y expresiones cínicas e irónicas para agitar las emociones y despertar indignación frente a las circunstancias. En la primera elección del actual rector de la UBA, en 2013, hicieron hincapié en: el carácter «antidemocrático» de los comicios electorales, la perpetuación de la toma de decisiones administrativas en manos de «los mismos», y la «aristocracia que, según afirmaban, «sólo permite a una casta de profesores titulares postularse y auto-elegirse». Arengaron contra el rectorado diciendo que allí «las cosas se cocinan a puerta cerrada», y que a largo plazo el fin último del régimen es poner la educación, y con ello a la universidad, al servicio del mercado, distanciándola de los sectores que carecen de los medios económicos para acceder al conocimiento. Denunciaron que la ausencia de una verdadera democracia en los órganos de co-gobierno es una de las causales de los ajustes de la educación pública. Y subrayaron que los confines hegemónicos del poder en la universidad son los de convertirla en el reducto educativo de la burguesía.

Mediante el proceso del pronóstico proponen vías alternativas al atropello y exigen su cumplimiento. Plantean un esquema democrático que concede la supremacía administrativa a los estudiantes, en primera instancia, y a los docentes auxiliares y profesores interinos, en segunda. En él promueven la elección directa de decanos y rectores bajo el criterio «una persona un voto» junto al funcionamiento de cuerpos colegiados con representación «más democrática» por claustros; 
plantean la posibilidad de que los más de 360,00o estudiantes de la institución tengan mayoría en todos los órganos de co-gobierno, en juntas de carrera, consejos directivos y consejo superior y, además, que todos los no docentes y auxiliares tengan voz y voto en los consejos. Como parte de la pelea por el reconocimiento de la gran mayoría de docentes ad honorem proponen un único claustro cuyos miembros sean elegidos por todo el plantel y, entre otras cosas, que todos los cargos estén sujetos a revocatorias del mandato, con base en asambleas interclaustros, en donde los estudiantes puedan también decidir sobre las cuestiones centrales de las carreras, de la vida de las facultades y de las universidades. Las tácticas para concretar esos propósitos pasan por la realización de campañas de propagación, información, y debate sobre los estatutos para la elección de las autoridades universitarias, entre otras.

El proceso de motivación incluye llamados a la movilización, la producción de incentivos públicos (Olson 1992), la explicación del perjuicio colectivo, la remembranza de las viejas hazañas y la promesa de futuras victorias. Los estudiantes aprecian la problemática universitaria como un asunto complejo de interés general y resaltan la responsabilidad de la población estudiantil en el asunto. Afirman que no solamente un cambio en la cantidad de representantes de cada claustro en los órganos de gobierno, sino el desafío por el cual todo el gremio se puede transformar en sujeto activo de la vida universitaria, en decisor de su función y su orientación social; y que el ataque a la educación pública es un ataque al bienestar universitario, y con ello al acceso y a la permanencia en la universidad. Suelen recordar los logros obtenidos cuando sus luchas han sido masivas, e insisten en el carácter social de la problemática.

La identidad colectiva pasa por las acciones que proporcionan el soporte para la definición de expectativas, al igual que para el cálculo de los costes y beneficios de la movilización. De acuerdo con los estudios teóricos, es este factor el que facilita la integración de los individuos en la acción colectiva (Tarrow 2004), y sin su presencia no es posible explicar cómo se condensa la acción (Melucci 1999). Recurrir a ella comprende dos expresiones que amalgaman la masificación: acciones «defensivas», en la medida en que se fundan en relaciones de igualdad y diferencia; y acciones «ofensivas», en la medida en que expresan la oposición y el conflicto (Touraine 1987).

La formación de un «nosotros» necesariamente se estable en relación con otro o a otros. Este proceso no es lineal, sino que se produce por la interacción, la negociación y la oposición de diferentes orientaciones. Sin él la injusticia no se puede percibir como tal, ni se pueden hacer los cálculos de las ganancias y las pérdidas (Melucci 1999; 1999). La identidad inherente al nosotros permite señalar al adversario, blanco y objeto de la movilización, reconocerse a sí mismos frente a éste, como su antagonista, e identificar a un tercero como directo afectado y potencial aliado. Mediante la interpretación del contexto, y sobre la base de un conflicto y varios agentes antagónicos, los estudiantes afianzan su identidad como protagonistas y construyen dos más: la de sus adversarios y la de sus audiencias. Incluyendo la propia, cada una representa un «campo de identidad», esto es, un conjunto de identidades reconocidas o atribuidas, construidas colectivamente: el campo de los «protagonistas» contiene atribuciones que los estudiantes hacen sobre sí mismos y sobre el gremio; el de los «antagonistas», atribuciones de identidad con 
las cuales detallan a sus rivales, y a quienes entran en conflicto con ellos, sean otras agrupaciones, sujetos colectivos, funcionarios políticos o agentes institucionales; el campo de las «audiencias» incluye prerrogativas referentes a los simpatizantes y aliados potenciales. Los marcos de diagnóstico, pronóstico y motivación son fundamentales en la conformación de todos (Hunt, Benford y Snow 2006).

\section{2. $\quad$ Dimensión dramatúrgica}

Los procesos operativos de la acción colectiva estudiantil ponen en evidencia la trama de la protesta, movilizan los saberes y experiencias acumuladas, y se proponen integrar a los espectadores a la lucha. Pensarlos bajo la metáfora del drama permite dimensionarlos «como si fueran performances artísticamente diseñados para crear y sostener la atención y el interés de su auditorio» (Gusfield 2014, 288). Su puesta en escena incluye el despliegue de estrategias y campañas de movilización que tienen por objetivo integrar y conmocionar a sus simpatizantes. Estas refieren puntualmente a la organización de esas formas (McCarthy 1999; Zald 1999; Tarrow 2004); y a los repertorios de acción que implementan en ellas (Tilly 2000; Zibechi 2003) que fueron aludidos en el numeral 2.6. A la pregunta por el uso de éstas un integrante de la agrupación USG respondió lo siguiente:

Y bueno, dependiendo del punto en el que esté la confrontación. Si es un conflicto que recién empieza a desarrollarse, por general la primera tarea es la propaganda de ese conflicto, que todos se enteren de que hay un conflicto, cuál es el conflicto y por qué surge. Cuando se puede juntar una masa considerable de gente que esté dispuesta a discutir sobre ese asunto: para dónde llevarlo, si estamos de acuerdo, si estamos en contra, cómo lo vamos a solucionar; por lo general se hacen asambleas. De las asambleas pueden salir medidas de lucha, como son la toma de las facultades, interrupciones de calles; este, movilizaciones a lo que es el Consejo Directivo para presionar las autoridades; este, pasadas por curso para seguir difundiendo, y lo más clásico: una tirada de afiches referente al conflicto en general. Si la policía viene a reprimirnos pues obviamente nos vamos a defender, pero nunca somos los que incitamos a la violencia, no consideramos que estemos en un clima social, el cual nos permita tomar medidas extremas.

Las campañas sintetizan el esfuerzo «público», «organizado» y «sostenido», para llevar las reivindicaciones colectivas a las autoridades (Tilly 2000). Estas acciones en ocasiones logran producir «ciclos de acción», es decir:

Una fase de intensificación de los conflictos y la confrontación en el sistema social, que incluye una rápida difusión de la acción colectiva de los sectores más movilizados a los menos movilizados, un ritmo de innovación acelerado en formas de confrontación, marcos nuevos o transformados para la acción colectiva, una combinación de participación organizada y no organizada y una secuencia de interacción intensificada entre disidentes y autoridades. Esta confrontación generalizada produce efectos externos que proporcionan una ventaja, al menos temporal, a los disidentes y les permite superar la debilidad en su base de recursos; exige a los Estados la organización de estrategias de respuesta amplias, bien sean represivas, facilitadoras o una combinación de las dos; y produce un resultado general mayor que la suma de las 


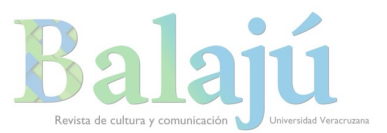

consecuencias de una serie de acontecimientos desconectados. (Tarrow 2004, 202-203)

En una y otros la movilización de las bases es elemental. Este proceso constituye el tejido conectivo de las estructuras racionales y motivacionales del demos estudiantil. $\mathrm{Su}$ realización es atribuible al conjunto de grupos que comparten los mismos principios, y aportan diferentes expresiones para denotar los aspectos concretos. Las «redes» (Melucci 1999) establecidas entre las agrupaciones, propician el vínculo de promotores y simpatizantes de la causa y aumentan el número de participantes; unen a la gente sobre el terreno, permiten superar los déficits de capital social, crear acuerdos, y enfrentarse a oponentes (Tarrow 2004). La FUA y las federaciones regionales, como la FUC o la FUBA, antaño han sido las encargadas de esa función y de establecer alianzas con otros actores sociales. Las coaliciones y frentes que se crean en el contexto de las contiendas, paradójicamente, suelen ser uno de los motivos de su fractura y letargo.

\section{Conclusiones}

Fenomenológicamente hablando, la protesta estudiantil involucra diferentes dimensiones de la vida social e implica diversos procedimientos que adquieren su consistencia en el tiempo y adoptan las particularidades del contexto social en el que tienen lugar. Siguiendo presupuestos epistémicos distintos al marxista -enfoque que hegemoniza este tema en Argentina- es prudente decir que la historia de este fenómeno en dicho territorio se encuentra atravesada, y en cierto grado determinada, tanto por la agencia de los regímenes administrativos como por partidos políticos locales. La acción colectiva inherente a él, responde a conflictos de intereses que son indisociables de la dinámica partidista en el Estado. Cada coyuntura nacional (el conservadurismo católico, las dictaduras, el populismo, la transición democrática, los ajustes económicos del liberalismo, el ascenso del progresismo al poder, etc.) ha representado una oportunidad para que los universitarios, en contra o a favor, incidan en su rumbo. Este factor explica su persistencia en el tiempo aun cuando sus protagonistas son pasajeros. La crisis económica que se vive en la actualidad, las problemáticas que exhibe, y la intensificación de las movilizaciones del gremio en torno a esas situaciones, son un fiel reflejo de ello.

En épocas de reflujo social el activismo de este sector suele concentrarse en asuntos académicos y en las contrariedades de la legislación universitaria así como de los estatutos de las casas de estudio, hechos que suelen pasar desapercibidos, quizá a falta de difusión, pero que en el fondo develan de manera clara las sinergias intrínsecas de esta expresión pues es allí, en los periodos de fugacidad, donde se constituyen los instantes visibles de la movilización. Los momentos más críticos de su continuidad han sido delineados por la represión, prohibición y persecución de su práctica. Las contrariedades que suele enunciar son el producto del trabajo mancomunado de las agrupaciones estudiantiles y la influencia de los principios ideológicos que esgrimen. Éstas constituyen una serie de redes (conceptuales, simbólicas, de transmisión de denuncias y de articulación con otras agrupaciones y sectores sociales) esenciales para la masificación del gremio. 
Las formas de actuar que siguen varían de acuerdo con el evento que las convoca. Sus principios ideológicos difieren por su adscripción política en partidarias e independientes. A comienzos del milenio se las definía como de izquierda pero hoy por hoy esa generalización resulta errónea por la existencia de agrupaciones oficialistas a la ultraderecha (algo así como contrarreformistas o golpistas, en épocas anteriores al retorno democrático). En todas son perceptibles una serie de recursos encadenados de los cuales los estudiantes son la causa y efecto. Ellos representan la piedra angular de la movilización en la medida en que realizan diversas acciones: delinean sus horizontes de pensamiento, configuran sus identidades, plantean objetivos y problemáticas, trazan las vías de resolución, establecen hechos que tienen correlación con la realidad empírica, definen los motivos, identifican antagonistas, combinan formas de actuar colectivamente, concretan alianzas, difunden su lucha y se proponen movilizar al demos universitario.

Buena parte de estos quehaceres consiste en actos simbólicos dirigidos a los espectadores, lectores u oyentes. Todos involucran procesos de deliberación que permiten por un lado organizar la forma que tomará la protesta, y por otro construir y fortificar los recursos de la organización. Su carácter admite su distinción en procesos cognitivos y procesos operativos, ambos funcionales a la coproducción de los recursos de las agrupaciones. La analogía con la dramaturgia y la retórica ilustra por qué unos y otros hacen eco, surten efecto, o no, en tanto dependen de las normas para hablar y de la cultura preestablecida en la sociedad. Fuera del conjunto de prácticas, signos y símbolos, que aquellas contienen, el lenguaje y los actos de la acción colectiva estudiantil carecen de sensatez. Su sentido se produce mediante elaboraciones conceptuales que incluyen la presentación de imágenes, categorías teóricas, justificaciones, relatorías y actos racionales. Todos animan el deseo de combatir a favor del gremio y en contra de sus adversarios, en la medida en que son reconocidos por los destinatarios. La problematización de la realidad que presentan, en pocas palabras, pasa por la lectura crítica de la forma de organización social imperante y de la vida cotidiana en general.

En este orden de ideas, los procesos cognoscitivos se basan en la construcción de los símbolos y significados de la movilización, mientras que los operativos se proponen conmocionar auditorios publicitando y arraigando el sentido producido en aquellos. En éstos, imagen y acción se articulan mediante performances dando vida material a las contrariedades que señalan. Vista en esta perspectiva, la protesta estudiantil se puede leer como un sistema de interacción en donde una serie de procedimientos, no rígidos y generalmente superpuestos, producen esquemas comprensibles mientras se retroalimentan en simultáneo, para politizar la realidad empírica y, en consecuencia, transformarla.

En fin, a cien años del Grito de Córdoba muchas de sus demandas se mantienen vigentes. La acción colectiva de las y los estudiantes argentinos desde entonces se ha convertido, en términos culturales, en una práctica tradicional que, pese a su fractura y letargo actual, si se le compara con la fuerza y unidad que desplegaba antes de la dictadura del 76, también se conserva latente. Su novedad más visible se manifiesta por una parte en la proliferación de organizaciones al igual que en el uso de las NTIC, y por otra en las demandas de género; las prácticas que estas últimas involucran se vuelven instrumentales a la toma de conciencia de un público particular, aspecto que implica una construcción simbólica y procedimientos especiales en los cuales el 
género masculino cumple un rol opuesto, sobremanera, al que realizaba hace un siglo cuando en las filas -y entre los cuadros- de la protesta estudiantil su activismo era predominante.

\section{Anexo}

Tabla 1. Agrupaciones por facultad que participaron en las elecciones para Centros e Estudiantes y Consejos Directivos del Claustro estudiantil de la UBA en 2013

\begin{tabular}{|c|c|c|c|}
\hline \multicolumn{4}{|c|}{ AGRUPACIONES Y FRENTES ESTUDIANTILES UBA 2013} \\
\hline \multirow{10}{*}{ DERECHO } & Nuevo Derecho & \multirow{10}{*}{$\begin{array}{l}\text { CIENCIAS } \\
\text { SOCIALES }\end{array}$} & Izquierda al frente \\
\hline & Franja Morada & & El Empuje \\
\hline & Pro & & UES/Vamos Sociales \\
\hline & Centeno/Mella & & Soc. $x$ el Cambio \\
\hline & Podemos & & SUR \\
\hline & FIT & & El Gleyzer \\
\hline & 14 is & & FNA \\
\hline & SUR & & MST \\
\hline & JUP & & \\
\hline & Univ para todos & & \\
\hline \multirow{10}{*}{$\begin{array}{l}\text { FILOSOFÍA Y } \\
\text { LETRAS }\end{array}$} & Izquierda al Frente & \multirow{10}{*}{$\begin{array}{c}\text { CIENCIAS } \\
\text { ECONÓMICAS }\end{array}$} & Nuevo Espacio \\
\hline & La Juntada & & MxE \\
\hline & FUP & & Pro \\
\hline & La Bemba & & La Belgrano \\
\hline & UNEM & & Fte. Bicentenario \\
\hline & Maríategui & & PTS \\
\hline & Marea & & SUR \\
\hline & Glayser & & $J \times E$ \\
\hline & is & & FAP \\
\hline & Vallese & & MST \\
\hline \multirow{9}{*}{$\begin{array}{l}\text { ARQUITECTURA } \\
\text { DISEÑOY Y } \\
\text { URBANISMO }\end{array}$} & Estudiantes $\mathrm{x}$ el Cambio & \multirow{9}{*}{ PSicología } & Izq al Frente \\
\hline & Coalición & & El Impulso \\
\hline & FADU Plural & & UNEM \\
\hline & Reforma & & LacAndPop \\
\hline & PTS & & CEPA \\
\hline & La Mella & & \\
\hline & BKF & & \\
\hline & Nueva FADU & & \\
\hline & CAUCE & & \\
\hline \multirow{7}{*}{ MEDICINA } & Nuevo Espacio & \multirow{7}{*}{$\begin{array}{l}\text { CIENCIAS } \\
\text { EXACTAS }\end{array}$} & Izq al Frente \\
\hline & El Frente & & FEM \\
\hline & Todos xCs Médicas & & Unidad \\
\hline & SUR & & L 9 \\
\hline & Miles & & SUR \\
\hline & CEPA & & Revira + BN \\
\hline & & & Gleyzer \\
\hline \multirow{6}{*}{ AGRONOMÍA } & LAI & \multirow{6}{*}{ INGENIERÍA } & MLI \\
\hline & FANA & & 7 de Sep \\
\hline & PO & & La Mella \\
\hline & La Cámpora & & UNEM \\
\hline & & & FEIN \\
\hline & & & EPA \\
\hline \multirow{5}{*}{$\begin{array}{c}\text { CIENCIAS } \\
\text { VETERINARIAS }\end{array}$} & Evet (po) & \multirow{5}{*}{ PSICOLOGÍA } & PO \\
\hline & La Tropilla & & Alianza \\
\hline & & & PCCE-La Cámpora \\
\hline & & & Is \\
\hline & & & UES \\
\hline \multirow{3}{*}{ odontología } & AFO & & \\
\hline & V-PAR(PO) & & \\
\hline & El Tio & & \\
\hline
\end{tabular}

Fuente. Elaboración propia partir de Juventud Informada, Diario Virtual 2013. 
Tabla 2. Agrupaciones por facultad que participaron en las elecciones para centros de estudiantes y consejos directivos del claustro estudiantil de la UBA en 2017.

\begin{tabular}{|c|c|c|c|}
\hline \multicolumn{4}{|c|}{ AGRUPACIONES Y FRENTES ESTUDIANTILES UBA 2017} \\
\hline \multirow{8}{*}{$\begin{array}{l}\text { FILOSOFÍA Y } \\
\text { LETRAS }\end{array}$} & $\begin{array}{c}\text { La Izquierda el Frente (En Clave } \\
\text { Roise) }\end{array}$ & \multirow{8}{*}{$\begin{array}{l}\text { CIENCIAS } \\
\text { SOCIALES }\end{array}$} & La Izquierda al Frente (En Clave \\
\hline & El Colectivo (La Cámpora+La Mella+Nuevo & & La Revuelta (MTS+Más+29 de Mayo) \\
\hline & Aquelarre & & La UES \\
\hline & Épica/Mariátegui & & Proyecto SocialestLa Mella \\
\hline & Franje Morada & & Nuevo Sociales (Franja Morada) \\
\hline & MTS & & Dignidad+Viejo Topo \\
\hline & SUR+CEPA & & Libres del Sur \\
\hline & La UES & & \\
\hline \multirow{8}{*}{ DERECHO } & & \multirow{8}{*}{$\begin{array}{c}\text { CIENCIAS } \\
\text { ECONÓMICAS }\end{array}$} & FIT (En Clave \\
\hline & Nuevo Derecho & & Roja+PTS+MXE2017+DSQ+PO+CAUCE+BASE \\
\hline & Franje Morada & & Nuevo Espacio \\
\hline & Acción Colectiva & & SOS+La Mella \\
\hline & Transformar Derecho & & PRO \\
\hline & Juntos (PRO) & & Alternativa Estudiantil \\
\hline & Frente de Izquierda (PTS+PO) & & Belgrano \\
\hline & Izquierda al Frente (N.Más+MTS) & & \\
\hline \multirow{7}{*}{$\begin{array}{l}\text { ARQUITECTURA } \\
\text { DISEÑOY Y } \\
\text { URBANISMO }\end{array}$} & $\begin{array}{c}\text { Somos FADU (Luis Bruno+Coalición+Franja } \\
\text { Morada) }\end{array}$ & \multirow{7}{*}{ PSICOLOGÍA } & $\begin{array}{l}\text { La Izquierda al Frente (En Clave } \\
\text { Roja+PTS+EPA+PO+IS+N.Más) }\end{array}$ \\
\hline & La Lista de los Estudiantes (CR+PO+La & & \\
\hline & $\begin{array}{c}\text { MELLA) } \\
\text { MELA) }\end{array}$ & & El Ipulso (SUR+La Mella \\
\hline & La Nueva Fadu+Nuevo Encuentro & & \\
\hline & La Izquierda al Frente (Contraimagen+PTS) & & Proyecto Psico \\
\hline & Proyectemos FADU+La Cámpora & & Inconsciente Colectivo \\
\hline & SUR+CEPA+MUE & & Psicologos para el pueblo \\
\hline \multirow{7}{*}{ MEDICINA } & $\begin{array}{l}\text { El Frente (PO+Cs Médicas }+29 \text { De } \\
\text { Mayo+CR+Más+Dignidad+MTS) }\end{array}$ & \multirow{7}{*}{$\begin{array}{l}\text { CIENCIAS } \\
\text { EXACTAS }\end{array}$} & FEM+La Mella \\
\hline & Nuevo Espacio & & Exactas puede más \\
\hline & Miles & & La Izquierda en Exactas+PO \\
\hline & Unidad & & CBB+La Dignidad \\
\hline & Proyectemos FADU+La Cámpora & & Lista Unidad+CEPA \\
\hline & La Mella & & \\
\hline & SUR+MUE+CEPA & & \\
\hline \multirow{6}{*}{ AGRONOMÍA } & Lista de agronomía independiente & \multirow{6}{*}{ INGENIERÍA } & Movimiento Linealmente Independiente \\
\hline & Frente amplio para una nueva agronomía & & Cambiemos \\
\hline & Abriendo caminos & & La Mella+Unidos por Ingeniería \\
\hline & ATP & & Izquierda en Ingeniería \\
\hline & EVET+UJS & & Proyecto Ingeniería \\
\hline & & & Franja Morada \\
\hline \multirow{5}{*}{$\begin{array}{c}\text { CIENCIAS } \\
\text { VETERINARIAS }\end{array}$} & La Tropilla & \multirow{5}{*}{$\begin{array}{l}\text { FARMACIA Y } \\
\text { BIOQUÍMICA }\end{array}$} & Antídoto \\
\hline & Unión Veterinaría & & Nuevo Espacio \\
\hline & Cambiemos & & Lista $1 \mathrm{~K}$ \\
\hline & Nuevo Espacio & & Izquierda Socialista \\
\hline & La Mella & & \\
\hline \multirow{3}{*}{ ODONTOLOGÍA } & Alumnos de la Facultad de Odontología & & \\
\hline & V+PAR & & \\
\hline & Nuevo Encuentro & & \\
\hline
\end{tabular}

Fuente. Elaboración propia a partir de: La Izquierda Diario, 2017. 


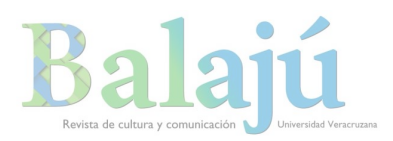

\section{Bibliografía}

ALBORNOZ, O. 1971. El significado del movimiento estudiantil. Corporación de promoción universitaria. Santiago de Chile: CPU Serie de Aportes Universitarios no. 5 .

ARDITI, B. 1995. "Rastreando lo político". Revista de Estudios Políticos, no. 87 (eneromarzo): http//www.cepc.es/rap/Publicaciones/Revistas/3/REPNE_o87_334.pdf

ARRIONDO, L. 2011. "Universidad y Política. El movimiento estudiantil en los 8os". La $\begin{array}{lllll}\text { revista del } & \text { CCC, } & \text { no. } & 11 & \text { (enero-abril) }\end{array}$ http://www.centrocultural.coop/revista/articulo/209/issn 1851-3263

BARLETTA, A. 2006. "Algunas impresiones sobre el movimiento estudiantil”. Cuestiones de Sociología, Revista de Estudios Sociales, no. 3 (otoño): 221-231.

BIAGINI, H. 2000a. La Reforma Universitaria. Antecedentes y consecuentes. Buenos Aires: Leviatán.

BIAGINI, H. 200ob. Utopías juveniles de la bohemia al Che. Buenos Aires: Leviatán.

BONAVENA, P., S. Califa y M. Millán. 2007. El movimiento estudiantil argentino historias con presente. Buenos Aires: Ediciones Cooperativas.

BONAVENA, P. y M. Millán. 2012. "El movimiento estudiantil en la actualidad argentina: una aproximación sociohistórica”. Observatorio Social de América Latina, no. 31 (XIII): 105-122.

BONAVENA, P. y M. Millán. 2015. "El movimiento estudiantil técnico bonaerense frente a la Ley Fantasma en 1972”. Ponencia presentada en el VI Congreso Regional de Historia e Historiografía. Santa Fe: Facultad de Humanidades y Ciencias de la Universidad Nacional del Litoral, 28 y 29 de mayo.

BULLENTINI, A. 2018. "Están empecinados en destruir la universidad”. Página 12, Universidad, 31 de agosto. https://www.pagina12.com.ar/138989-estan-empecinados-endestruir-la-universidad

BRUNNER, J. 1986. "El movimiento estudiantil ha muerto. Nacen los movimientos estudiantiles". En La juventud universitaria en América Latina, compilado por J. Tedesco y H. Blumenthal. Caracas: CRECELAC.

BUCHBINDER, P. 1997. Historia de la Facultad de Filosofía y Letras. Universidad de Buenos Aires. Buenos Aires: Editorial Universitaria de Buenos Aires.

BUCHBINDER, P. 2005. Historia de las universidades argentinas. Buenos Aires: Editorial Suramericana.

BUCHBINDER, P. y M. Marquina. 2008. Masividad, heterogeneidad y fragmentación: el sistema universitario argentino 1983-2007. Colección 25 años 25 libros. Buenos Aires: UNGS/ Biblioteca Nacional.

BUCHBINDER, P., P. Bonavena y S. Califa (Comps.). 2010. Apuntes sobre la formación del movimiento estudiantil argentino (1943-1973). Buenos Aires: Final Abierto.

CANTINI, J. 1996. La autonomía y la autarquía de las universidades nacionales. Buenos Aires: Academia Nacional de Educación de Buenos Aires, Argentina.

CALIFA, S. 2004. El movimiento estudiantil reformista de la Universidad de Buenos Aires. De una fuerza social hacia otra. 1943-1958. (Tesis inédita). Maestría en Sociología de la Cultura y Análisis Cultural, Instituto de Altos Estudios Sociales, Universidad Nacional de San Martín. 
CALIFA, S. 2007. La militancia estudiantil en la Universidad de Buenos Aires entre golpe y golpe, 1943-1955. En El movimiento estudiantil argentino historias con presente, de P. Bonavena, S. Califa y M. Millán, 31-79. Buenos Aires: Ediciones Cooperativas.

CASTRO, L. 2016. Fundamentos de la acción colectiva estudiantil: Análisis de caso, Facultad de Filosofía y Letras, Universidad de Buenos Aires, segundo cuatrimestre de 2013 (Tesis de posgrado). Magíster en Ciencias Sociales, Facultad de Humanidades y Ciencias de la Educación, Universidad Nacional de La Plata. http://www.memoria.fahce.unlp.edu.ar/tesis/te.1230/te.1230.pdf

CARLI, S. 2006. "La experiencia universitaria y las narrativas estudiantiles. Una investigación sobre el tiempo presente", Revista Sociedad, no. 25, Facultad de Ciencias Sociales UBA, Prometeo: 29-46.

CARLI, S. 2012. El estudiante universitario: hacia una historia del presente de la educación pública. Buenos Aires: Siglo XXI.

CARLI, S. (Dir. y Comp.). 2014. Universidad pública y experiencia estudiantil. Historia política y vida cotidiana. Buenos Aires: Miño y Dávila Editores.

CEBALLOS, C. 1985. Los estudiantes universitarios y la política. Buenos Aires: CEAL.

CEFAÏ, D. 2008. Los marcos de la acción colectiva. En Sujetos, movimientos y memorias. Sobre los relatos del pasado y los modos de confrontación contemporáneos, editado por Ana Natalucci, 49-79. La Plata: Al Margen.

CEFAÏ, D. (2014). «Investigar los problemas públicos: con y más allá de Joseph Gusfield». En La cultura de los problemas públicos, de J. Gusfield, 11-6o. Buenos Aires: Siglo XXI.

CEFyL (2). CEFyL web site. http://cefyl.net/

CICOUREL, A. 1982. "La entrevista". En El método y la medida en sociología, de A. Cicourel, 74-100. Madrid: Editorial Nacional.

CHIROLEU, A., C. Suasnabar, y L. Rovelli. 2012. Política universitaria en la Argentina: revisando viejos legados en busca de nuevos horizontes. Buenos Aires: Instituto de Estudios y Capacitación/ Federación Nacional de Docentes/ Universidad Nacional General Sarmiento.

CLARÍN. 2002. "Elección de la asamblea universitaria UBA: Jaim Etcheverry, nuevo rector" http://edant.clarin.com/diario/2002/04/03/s-03608.htm

CLARÍN. 2017. "La UBA elige rector en medio de protestas estudiantiles y docentes". https://www.clarin.com/sociedad/uba-elige-rector-medio-protestas-estudiantilesdocentes_o_SkWgLTfZG.html

CORTÉS, C. y V. Kandel. 2002. "Reflexiones en torno a las nuevas formas de participación política estudiantil en la vida política de la universidad". Revista Fundamentos en Humanidades, no. 5-6 (febrero-marzo): 23-24.

CORTEZ, Martín. ¿ (s.f.). iUna ideología del afuera? http://www.diariovive.org/notas/cortez1.htm

DELICH, F. 1986. Megauniversidad. Buenos Aires: EUDEBA.

FUNES, F. 2 de septiembre 2009. "Después de los votos: la izquierda orgánica y el reformismo celebraron los resultados que obtuvieron en las elecciones de consejeros y de centros en las facultades de la Universidad de Buenos Aires”. Página 12. Política: 9 .

GEDDES, D. 2 de septiembre 2008. "La Cámpora no logra hacer pie en los centros de estudiantes de la UBA”. Clarín. Universidad: 16.

GUSFIELD, J. 2014. La cultura de los problemas públicos. Buenos Aires: Siglo XXI. 
HALPERIN, D. 1962. Historia de la Universidad de Buenos Aires. Buenos Aires: EUDEBA. HUNT, S., R. Benford y D. Snow. 2006. "Marcos de acción colectiva y campos de identidad en la construcción social de los movimientos”. En El análisis de los marcos en la sociología de los movimientos sociales, coordinado por A. Chihu, 155-188. México: Universidad Autónoma Metropolitana.

Juventud Informada. Diario Virtual, Universidad. (8 de septiembre 2013). "Resultados de las elecciones UBA". http://www.juventudinformada.com.ar/2013/o9/o8/en-vivoresultados-de-las-elecciones-de-la-uba/

Juventud Informada. Diario Virtual, Universidad. 16 de septiembre de 2017. "Resultados de las elecciones UBA”. http://www.juventudinformada.com.ar/2017/09/16/resultados-de-laseleccionesuba/

KROTSCH, Pedro. 2014. "Los universitarios como actores de reformas en América Latina: ¿han muerto los movimientos estudiantiles?”, En Universidad pública y experiencia estudiantil. Historia, política y vida cotidiana, dirección y compilación de S. Carli, 141-163. Buenos Aires: Miño y Dávila Editores.

LARAÑA, E. 1999. La construcción de los movimientos sociales. Madrid: Alianza Editorial.

La Izquierda, Diario. 15 de septiembre de 2017. "Elecciones UBA". http://www.laizquierdadiario.com/Elecciones-UBA-2017-enterate-aca-de-todoslos-resultados

LIAUDAT, M., S. Liaudat y N. Pis Diez. 2012. En las aulas y en las calles. Antecedentes, continuidades y rupturas de una década del movimiento estudiantil universitario argentino 2002-2011. Buenos Aires: Herramienta Ediciones.

MARIÁTEGUI, J. 2012. 7 Ensayos de interpretación de la realidad peruana. Lima: Biblioteca Amauta.

MCADAM, D., McCarthy, J. y Zald, M. (Eds.). 1999. Movimientos sociales: perspectivas comparadas. Oportunidades políticas, estructuras de movilización y marcos interpretativos culturales. Madrid: Ediciones Istmo.

MCCARTHY, J. 1999. Adoptar, adaptar e inventar límites y oportunidades. En Movimientos sociales: perspectivas comparadas. Oportunidades políticas, estructuras de movilización y marcos interpretativos culturales, editado por D. McAdam, J. McCarthy y M. Zald, 205-220. Madrid: Ediciones Istmo.

MELUCCI, A. 1994. "Asumir un compromiso: identidad y movilización en los movimientos sociales”. Revista Zona Abierta, no. 69: 153-180.

MELUCCI, A. 1999. Acción colectiva, vida cotidiana y democracia. México: Colegio de México.

MITRE, S. (Dir.). 2011. El estudiante. [Película] Argentina.

MOUFFE, C. 2007. En torno a lo político. Buenos Aires: FCE.

MUNCK, G. 1995. "Algunos problemas conceptuales en el estudio de los movimientos sociales". Revista Mexicana de Sociología, no. 3: 16-40.

NAISHTAT, F. y M. Toer (Eds.). 2005. Democracia y representación en la universidad. El caso de la universidad de buenos aires desde la visión de sus protagonistas. Buenos Aires: Biblos Editorial.

NOSIGLIA, M. y Mulle, V. 2009. "Las transformaciones en el gobierno de las universidades argentinas: Análisis del caos". Revista Argentina de Educación Superior, no. 1 (año 1): 173-200. 
OLSON, M. 1992. La lógica de la acción colectiva. Bienes públicos y la teoría de los grupos. México: Limusa/ Noriega Editores.

PÁGINA 12. 4 de diciembre de 2017. "Barbieri, por cuatro años más frente a la UBA". https://www.pagina12.com.ar/80410-barbieri-por-cuatro-anos-mas-al-frente-dela-uba

PICOTTO, D. y P. Vommaro. 2010. “Jóvenes y política: las agrupaciones estudiantiles independientes de la Universidad de Buenos Aires”. Nómadas, no. 32 (abril): 149161.

PORTANTIERO, J. 1978. Estudiantes y Política en América Latina. En Estudiantes y política en América Latina. El proceso de la reforma universitaria (1918-1938). México: Siglo XXI.

PORTANTIERO, J. 2001. "El sentido de la universidad pública". En Fílosofías de la universidad y conflicto de racionalidades, compilado por F. Naishtat, A. García y S. Villavicencio, S.: 83-86. Buenos Aires: Colihue Universidad.

QUIRÓS, J. 2014. Diccionario del léxico corriente de la política argentina. Palabras de democracia (1983-2013), coordinado por A. Adelstein y G. Vommaro. Buenos Aires: Universidad Nacional General Sarmiento.

RASCHKE, J. 1994. "Sobre el concepto de movimiento social”. Zona Abierta, no. 69: 121134.

REVILLA, M. 1994. "El concepto de movimiento social: acción, identidad y sentido". Zona Abierta, no. 69: 181-213.

RIEZNIK, P. 2008. “La reforma universitaria de 1918: el primer Cordobazo”. Educación $\begin{array}{llll}\text { Superior cifras } y \text { hechos, } & \text { (mayo-agosto): } & \text { 16-23. }\end{array}$ http://computo.ceiich.unam.mx/webceiich/docs/revis/33Bolo36.pdf

ROCA, D. $1918 . \quad$ Manifiesto Liminar.

https://wold.fder.edu.uy/archivo/documentos/manifesto-reformauniversitaria.pdf

ROMERO, F. 2009. "Sobre estudiantes universitarios y movimiento estudiantil: problemas teóricos conceptuales”. En Los Estudiantes Organizaciones y Luchas en Argentina y Chile, de F. Romero, 9-24. Bahía Blanca: Libros en Colectivo.

ROMERO, J. y L. Romero. 1983. Historia de cuatro siglos. Buenos Aires: Editorial Abril.

ROMERO, R. 1998. La lucha continua. El movimiento estudiantil argentino en el siglo XX. Buenos Aires: Eudeba/ FUBA.

ROVELLI, L. 2012. "Dimensiones, actores y dilemas de gobierno del sistema y de las universidades públicas en Argentina”. En Política universitaria en la Argentina: revisando viejos legados en busca de nuevos horizontes, de A. Chiroleu, C. Suasnábar, C. y L. Rovelli, 33-48. Buenos Aires: IEC/ Universidad Nacional de General Sarmiento.

SADABA, I. Roig, G. 2004. "Nodo 50. Territorio virtual para los movimientos sociales y la acción política". En La red es de todos. Cuando los movimientos sociales se apropian de internet, editado por M. Sáez, 195-221. Madrid: Editorial Popular.

SALAS, A. 31 de agosto de 2018. "Movilizaciones y crisis universitaria en el gobierno de Mauricio Macri”. En CELAG, Análisis Político. http://www.celag.org/movilizaciones-y-crisis-universitaria-gobierno-macri/

SCHMITT, C. 1998. El concepto de lo político. Madrid: Alianza.

SIGAL, P. 2 de diciembre de 2006. "La pelea por el poder pide más dialogo y el éxodo de alumnos una mejor gestión”. Clarín. No. 24421 (año LXIX): 4. 
SNOW, D. y R. Benford. 2006. "Ideología, resonancia de marcos y movilización de los participantes”. En El análisis de los marcos en la sociología de los movimientos sociales, coordinado por A. Chihu, 83-117. México: Universidad Autónoma Metropolitana.

SNOW, D. y Benford, R. 2006. "Marcos maestros y ciclos de protesta”. En El análisis de los marcos en la sociología de los movimientos sociales, coordinado por A. Chihu, 119153. México: Universidad Autónoma Metropolitana.

SUASNÁBAR, C. 2012. "El marco normativo de las universidades y el debate sobre la autonomía universitaria: una lectura desde la producción académica”. En Política universitaria en la argentina: revisando viejos legados en busca de nuevos horizontes, de A. Chiroleu, C. Suasnábar y L. Rovelli, L., 69-86. Buenos Aires Argentina: IEC/ Universidad Nacional de General Sarmiento.

TARROW, S. 1999. "Estado y oportunidades: la estructuración política de los movimientos sociales2. En Movimientos sociales: perspectivas comparadas. Oportunidades políticas, estructuras de movilización y marcos interpretativos culturales, editado por D. McAdam, J. McCarthy y M. Zald, 71-99. Madrid: Ediciones Istmo.

TARROW, S. 2004. El poder en movimiento. Los movimientos sociales, la acción colectiva y la política. Madrid: Alianza Editorial.

TILLY, C. 2000. "Acción colectiva”. Apuntes de investigación, no. 6: 9-32.

TILLY, C. y L. Wood. 2010. Los movimientos sociales 1768-20o8. Barcelona: Editorial Crítica.

TOURAINE, A. 1987. "Los movimientos sociales: ¿̇objeto particular o problema central del análisis sociológico?”. En El regreso del actor, de A. Touraine, 93-115. Buenos Aires: Eudeba.

TOURAINE, A. 1997. ¿Podremos vivir juntos? México: Fondo de Cultura Económica.

TÜNNERMANN, C. 2008. Noventa años de la Reforma Universitaria de Córdoba: 19182008. Buenos Aires: Consejo Latinoamericano de Ciencias Sociales.

URRESTI, M. 2000. "Paradigmas de la participación juvenil: un balance histórico". En La participación social y política de los jóvenes en el horizonte del nuevo siglo, compilación de S. Balardini, 177-204. Buenos Aires: Consejo Latinoamericano de Ciencias Sociales.

VEGA, N. 2010. 2Repertorios discursivos y construcción de identidades en el movimiento estudiantil santafesino durante el ongianato". En Apuntes sobre la formación del movimiento estudiantil argentino (1943-1973), compilación de P. Buchbinder, J. Califa. y M. Millán, 131-158. Buenos Aires: Final Abierto.

ZALD, M. (1999). "Cultura, ideología y creación de marcos estratégicos". En Movimientos sociales: perspectivas comparadas. Oportunidades políticas, estructuras de movilización y marcos interpretativos culturales, editado por D. McAdam, J. McCarthy y M. Zald, 49-70. Madrid: Ediciones Istmo.

ZEMELMAN, H. 2009. Uso crítico de la teoría. En torno a las funciones analíticas de la totalidad. México: Instituto Politécnico Nacional.

ZIBECHI, R. 2003. "Los cambios en las formas de protesta social". En Genealogía de la revuelta, de R. Zibechi, 21-36. Argentina: Letra Libre. 